\title{
LA DIMENSIÓN EXTERNA DEL DERECHO DE LA UNIÓN EUROPEA EN MATERIA DE REFUGIO Y ASILO: UN EXAMEN DESDE LA PERSPECTIVA DEL NON-REFOULEMENT
}

\author{
JOANA ABRISKETA URIARTE' \\ joana.abrisketa@deusto.es
}

Cómo citar/Citation

Abrisketa Uriarte, J. (2017).

La dimensión externa del derecho de la Unión Europea en materia de refugio y asilo: un examen desde la perspectiva del non-refoulement. Revista de Derecho Comunitario Europeo, 56, $119-158$. doi: https://doi.org/10.18042/cepc/rdce.56.04

\section{Resumen}

El artículo analiza los problemas que presenta la externalización de los controles migratorios impulsada en el marco de la dimensión externa de la Unión Europea. El examen se realiza desde la perspectiva del alcance del principio de non-refoulement. La Convención de Ginebra sobre el Estatuto de los Refugiados de 1951 no contiene disposición alguna sobre la aplicación ratione loci de dicho principio. Es obvio que el non-refoulement tiene efectos cuando el refugiado se halla dentro del territorio del Estado de recepción o en sus fronteras. Este es el escenario evocado por la Convención de Ginebra. Últimamente, también se ha recurrido a la aplicación extraterritorial del principio cuando las medidas de control se llevan a cabo en el ejercicio de la jurisdicción por parte del Estado, aunque el refugiado se halle en alta mar. Sin embargo, cuando el potencial refugiado aún no ha salido de su territorio, debido a las medidas de control migratorio "externalizadas», difícilmente puede apelar a su derecho al non-refoulement, porque aún no es un refugiado. En tal caso, quien es destinatario de estas medidas, que le impiden salir de su propio país, podría solicitar un visado hu-

1 Profesora titular de Derecho Internacional Público y Relaciones Internacionales, Universidad de Deusto. 
manitario o invocar el derecho a salir de su país, pero con limitaciones importantes. Tras el análisis de la jurisprudencia del Tribunal Europeo de Derechos Humanos más relevante, y en menor medida, del Tribunal de Justicia de la Unión Europea, el artículo confirma la necesidad de respuestas jurídicas más precisas que las actualmente vigentes en lo que se refiere a la compatibilidad entre la dimensión externa del asilo y del refugio que preconiza la Unión Europea y el principio de non-refoulement.

\section{Palabras clave}

Dimensión exterior de la Unión Europea; externalización; extraterritorialidad; non-refoulement; derecho a salir del propio país.

\section{THE EXTERNAL DIMENSION OF THE EUROPEAN UNION LAW IN THE FIELDS OF REFUGE AND ASYLUM: A STUDY FROM THE PERSPECTIVE OF NON-REFOULEMENT}

\section{Abstract}

This article analyses the problems posed by the externalization of migratory controls proposed within the framework of the external dimension of the European Union. The focus of the study is on the perspective of the principle of non-refoulement. The Geneva Convention on the Statute of Refugee of 1951 contains no article relating to the application ratione loci of the non-refoulement principle. It is obvious that such a principle becomes effective when the refugee is inside the receiving State or at its borders. This is the scenario evoked by the Geneva Convention. Recently, the extraterritorial application of the principle has been invoked when the control measures have been performed in the exercise of jurisdiction by the State parties of the Geneva Convention, though the refugees may be on the high seas. However, the extent of the obligation of non-refoulement is not so evident when the potential refugee is not yet outside his territory due to «externalized» migratory control measures. In such a case, the individuals subject to a measure of migratory control which impedes them departing from their own country could apply for a humanitarian visa or appeal to the right to leave, but with important limitations. After analyzing the most relevant jurisprudence of the ECtHR and to a lesser extent that of the CJUE, the article confirms the necessity of more precise legal answers than the ones in force as regards the compatibility between the external dimension of refugee and asylum of the EU and the principle of non-refoulement.

\section{Keywords}

External dimension of the European Union; externalization; extraterritoriality; non-refoulement; right to leave one's country. 


\section{LA DIMENSION EXTÉRIEURE DU DROIT DE L'UNION EUROPÉENNE EN MATIÈRE DE REFUGE ET D'ASILE : UN ANALYSE DU POINT DE VUE DU PRINCIPE DE NON-REFOULEMENT}

\section{Résumé}

Le présent article analyse les problèmes posés par l'externalisation des contrôles migratoires promue dans le cadre de la dimension extérieure de l'Union Européenne. L'étude est une analyse du point de vue de la portée du principe de non-refoulement. La Convention de Genève de 1951 relative au statut des réfugiés ne contient aucune disposition relative à l'application ratione loci de ce principe. Il est évident que le principe de non-refoulement a des effets lorsque le réfugié se trouve sur le territoire de l'État d'accueil ou à ses frontières. Il s'agit du scénario évoqué par la Convention de Genève. Dernièrement, il a également été fait appel à l'application extraterritoriale de ce principe dans le cas où ces mesures de contrôle sont réalisées par un État dans le cadre de sa juridiction, quand bien même le réfugié se trouvait en haute mer. Cependant, quand le réfugié potentiel n'a pas encore quitté son territoire à cause de mesures de contrôle des flux migratoires «externalisées», il peut difficilement invoquer son droit de non-refoulement parce qu'il n'est pas encore un candidat réfugié vis-à-vis de l'État d'accueil. Dans ce cas, la personne faisant l'objet de ces mesures, qui l'empêchent de sortir de son propre pays, pourrait demander un visa humanitaire ou invoquer le droit de quitter le territoire, mais avec des limitations importantes. Après l'analyse de la jurisprudence du TEDH qui est la plus déterminante, et de la Cour de Justice de l'Union Européenne impactant dans une moindre mesure, l'article confirme la nécessité de réponses juridiques plus précises en ce qui concerne la compatibilité entre la dimension extérieure du droit d'asile et au refuge préconisé para l'Union Européenne avec le principe de non-refoulement.

\section{Mots clés}

Dimension extérieure de l'Union Européenne; externalisation; extraterritorialité; non-refoulement; le droit du sortir du pays. 


\section{SUMARIO}

I. INTRODUCCIÓN. II. LA EXTERNALIZACIÓN DEL CONTROL MIGRATORIO:

1. Hacia la construcción de fronteras virtuales. 2. La dimensión externa de la Unión Europea como marco político y estratégico y los acuerdos de asociación como opción. III. EL NON-REFOULEMENT Y SU ÁMBITO DE APLICACIÓN RATIONE LOCI: 1. Los límites del principio de non-refoulement. 2. Ámbito de aplicación territorial: antecedentes en el derecho comparado. 3. Ámbito de aplicación extraterritorial: algunos criterios jurisprudenciales del TEDH y del TJUE. IV. LA ESCASA DENSIDAD NORMATIVA DEL DERECHO A SALIR DEL PROPIO PAÍS. V. CONCLUSIONES.

\section{INTRODUCCIÓN}

La Unión Europea (UE) tiende a externalizar los controles de entrada de extranjeros. Transfiere la vigilancia a terceros Estados y conduce, desde allí, los movimientos migratorios. En la misma línea, los Estados miembros gestionan los flujos de personas desde la distancia, antes de que estas se presenten en las fronteras o accedan al territorio de destino. En lugar de seguir el modelo tradicional, en función del cual el Estado decide sobre los derechos de entrada en el curso de la llegada de los solicitantes de asilo a los puestos fronterizos, el Estado o la propia UE emplean el territorio de un tercer Estado, bien para procesar allí las eventuales peticiones, bien para ejercer un impacto mayor y contener a los eventuales solicitantes ${ }^{2}$.

A ello se añade que este tipo de controles prefronterizos tiene como destinatarios los flujos mixtos. En la fase previa a la admisión, los solicitantes de asilo se confunden con los migrantes económicos y, en este contexto general, quedan sometidos a las mismas condiciones generales de la política

2 Guy GOODWIN-GILL, «The Extraterritorial Processing of Claims to Asylum or Protection: The Legal Responsibilities of States and International Organisations», University of Technology Sydney Law Review, núm. 9, 2007, pp. 26-40. 
migratoria ${ }^{3}$. Esto merma la aplicabilidad del principio de non-refoulement para quienes realmente podrían ser reconocidos como refugiados.

El control de las fronteras exteriores es un fin legítimo y consustancial al Estado. Representa una forma significativa del ejercicio de la soberanía y, como tal, se enmarca en un amplio corpus jurídico interno, europeo e internacional. El problema reside en que, en la actualidad, el ejercicio del control fronterizo en todas sus formas acusa el impacto del fenómeno migratorio en unas dimensiones sin precedentes. De ahí que se acentúe y refleje más que nunca la tensión entre la legitimidad de los Estados de controlar sus fronteras y el derecho al non-refoulement de los solicitantes de asilo y protección.

La hipótesis sobre la que se asienta este análisis es la siguiente: ante la fuerza del principio de non-refoulement, los Estados miembros de la UE tienden a sustraerse de su aplicación mediante la adopción de medidas ejecutables en el exterior. El problema radica en que, en principio, la Convención de Ginebra de 1951 (CG) evoca un escenario en el que solo al entrar en el territorio del Estado de destino produce efectos el principio de non-refoulement. Es decir, cuando el refugiado entra en contacto con la jurisdicción de dicho Estado, el non-refoulement empieza a surtir sus efectos. Sin embargo, la externalización no se corresponde con el escenario de la CG, puesto que, precisamente, las decisiones sobre el eventual asilo o protección internacio-

3 El Programa de Estocolmo de 2010 ya se refirió a la necesidad de identificar a las personas que necesiten protección internacional en «los flujos mixtos», en Consejo Europeo, Programa de Estocolmo. Una Europa abierta y segura que sirva y proteja al ciudadano, párr. 5 (DO C 115/1, de 4 de mayo de 2010). A este respecto, cabe añadir, como señala Fernando Arlettaz, que «no solo los flujos migratorios pueden ser mixtos, sino que también las razones que impulsan a una persona a migrar pueden ser una combinación de restricción de las libertades y necesidades económicas»; Fernando ARLETTAZ, La UE y la crisis humanitaria en el Mediterráneo: ¿quién tiene la obligación de dar protección?, en Cuadernos de Cultura de Paz, Seminario de Investigación para la Paz, 2016, Zaragoza, p. 3. Véase también Alejandro DEL VALLE, «Los refugiados, las fronteras exteriores y la evolución del concepto de frontera internacional», Revista de Derecho Comunitario Europeo, núm. 55, 2016, pp. 759-777, p. 761; Violeta MORENO LAX, "Must EU Borders Have Doors for Refugees? On the Compatibility of Schengen Visas and Carriers' Sanctions with EU Member States' Obligations to Provide International Protection to Refugees», European Journal of Migration and Law, núm. 10, 2008, pp. 315-364; y Ángeles SOLANES, «Derechos Humanos y Asilo: sobre las deficiencias del SECA y la regulación española», Anuario de la Facultad de Derecho de la Universidad de Alcalá, VII, 2014, pp. 181-210. 
nal se adoptan cuando el posible solicitante aún no ha salido de su país de origen o se halla en un Estado de tránsito. Ante esta situación, ¿qué tipo de relación se genera entre el Estado que externaliza la gestión migratoria y los destinatarios últimos de estas medidas?, ¿cabe considerar esta práctica el ejercicio de jurisdicción extraterritorial por parte del Estado o, en su caso, de la UE?, ¿puede entenderse que el non-refoulement solo se aplica cuando el refugiado ha salido del territorio o, por el contrario, podría leerse a la luz de criterios complementarios centrados en el ejercicio de la jurisdicción por parte del Estado sea cual sea el lugar en el que se encuentra el solicitante? Esta última perspectiva nos lleva a relacionarlo con las recientes construcciones jurisprudenciales del Tribunal Europeo de Derechos Humanos (TEDH) sobre la aplicación extraterritorial del Convenio Europeo de Derechos Humanos y Libertades Fundamentales (CEDH) y, en menor medida, dado el número más reducido de aportaciones sobre este objeto, del Tribunal de Justicia de la Unión Europea (TJUE).

Más de seis décadas después de la aprobación de la CG, cabe preguntarse por el alcance de las nuevas interpretaciones sobre su tenor literal, adaptadas a la nueva realidad. Esto es relevante, puesto que el principio de non refoulement constituye un elemento del acervo comunitario, recogido no solo en el art. 78 TFUE, sino también de manera explícita en el art. 19 (2) de la Carta de los Derechos Fundamentales de la Unión Europea (CDFUE), además de las numerosas alusiones a este en los instrumentos del derecho derivado.

En efecto, la evolución del concepto relativo al ejercicio de la jurisdicción del Estado permite lecturas que transcienden una base estrictamente territorial. A la luz de dicho avance, hoy se puede apelar a la aplicación extraterritorial de las normas de derechos humanos en determinadas ocasiones ${ }^{4}$. Esta doble construcción conceptual (territorial y extraterritorial) sirve de base al presente análisis. Su estudio en conjunto es útil para determinar si existe un ejercicio de jurisdicción por parte del Estado en tales supuestos, con las consecuencias jurídicas que podrían derivarse, e, incluso, para identificar los límites legales de la externalización.

Tras la presente introducción, el segundo apartado del artículo expone los rasgos que la externalización del control migratorio presenta en la actualidad,

4 Guy GOODWIN-GILL, "The Extra-Territorial Reach of Human Rights Obligations: A Brief Perspective on the Link to Jurisdiction», en Laurence BOISSON DE CHAZOURNES; Marcelo Gustavo KOHEN (eds.), International Law and the Quest for Its Implementation. Liber Amicorum Vera Gowlland-Debbas, Brill-Nijhoff, Leiden, 2010, pp. 293-308; y Silvia MORGADES, «La aplicación extraterritorial del Convenio Europeo de Derechos Humanos y Libertades Fundamentales: el concepto de jurisdicción en perspectiva cosmopolita», en Caterina GARCÍA SEGURA (dir.), La tensión cosmopolita. Avances y limites en la institucionalización del cosmopolitismo, Tecnos, Madrid, 2016, pp. 149-192. 
así como la evolución de la dimensión externa del derecho de la UE que le sirve de marco y de apoyo. A continuación, el tercer apartado recoge el estudio sobre los ámbitos de aplicación del principio de non-refoulement, esto es, el territorial y el extraterritorial. En el marco del presente análisis, el solicitante de protección internacional puede valerse del principio de non-refoulement si demuestra hallarse bajo la jurisdicción de un Estado miembro de la UE, de ahí que sea ineludible prestar atención a los avances jurisprudenciales en torno a la noción de jurisdicción y al alcance territorial y fundamentalmente extraterritorial de la CDFUE y del acervo comunitario en materia de asilo. También se hará mención en este apartado a la reciente aportación del abogado general Mengozzi por su interesante lectura acerca de la cláusula de jurisdicción del art. $1 \mathrm{CEDH}$ y su contraposición con la CDFUE, que prescinde en su texto de cláusula de jurisdicción alguna. El criterio que determina la aplicación de la CDFUE, por lo que se refiere a la acción de los Estados, es el que se inscribe en su art. 51.1, es decir, que se trate de actos en los que los Estados apliquen el derecho de la UE, según estima el abogado general en sus Conclusiones 5 . Finalmente, es inevitable explorar hasta qué punto los acuerdos migratorios y otras formas de externalización afectan al derecho a salir del propio país y sus límites. Las conclusiones del artículo confirman la necesidad de respuestas jurídicas más claras que las actualmente existentes.

\section{LA EXTERNALIZACIÓN DEL CONTROL MIGRATORIO}

\section{HACIA LA CONSTRUCCIÓN DE FRONTERAS VIRTUALES}

La expresión externalización de las fronteras describe un fenómeno complejo que abarca diferentes modalidades de control migratorio llevado a cabo por el Estado fuera de su territorio. La doctrina lo denomina control fronterizo externo ${ }^{6}$, política migratoria remota ${ }^{7}$, extraterritorialización de la

5 Conclusiones del abogado general Mengozzi presentadas en el asunto X C638/16 PPU, EU:C:2017:93, punto 97.

6 François CRÉPEAU, Delphine NAKACHE, Idil ATAK, «International Migration: Security Concerns and Human Rights Standards», Transcultural Psychiatry, núm. 44, 2007, pp. 311-324; y Helen O’NIONS, Asylum-A Right Denied. A Critical Analysis of European Asylum Policy, Routledge, London, 2014, p. 176.

7 Virgine GUIRAUDON, «Before the EU Border: Remote Control of the Huddle Masses», en Kees GROENENDIJK; Elspeth GUILD; Paul MINDERHOUD (eds.), In Search of Europe's Borders, Kluwer Law International, La Haya, 2003, pp. 191-214; 
política migratoria ${ }^{8}$, desterritorialización de los controles fronterizos ${ }^{9}$, neo-refoulement ${ }^{10} \mathrm{o}$ deslocalización virtual ${ }^{11}$. Estos términos — que solo sirven para hacer más compleja una cuestión de por sí políticamente sensible y legalmente insegura $^{12}$ - tienen como denominador común el objetivo de desplazar las tareas de control fronterizo al exterior del Estado ${ }^{13}$.

Las actividades que se presentan como ejemplos de externalización son las intervenciones de oficiales de inmigración en países terceros, la extensión de visados Schengen y las interceptaciones en los espacios marítimos ${ }^{14}$. Su exponente más extremo se traduce en aquellas medidas que fragmentan artificialmente el territorio del Estado. Se construyen así las llamadas zonas internacionales o de tránsito con el objetivo de establecer sistemas diferenciados $\mathrm{y}$, de este modo, eludir la aplicabilidad del régimen ordinario de protección en los territorios escindidos ${ }^{15}$. El empleo por parte de Australia de la isla de $\mathrm{Na}$ -

y Marten DEN HEIJER, Europe and Extraterritorial Asylum, Hart Publishing, Oxford, 2012.

8 Ricard ZAPATA, «La dimensión exterior de las políticas migratorias en el área mediterránea: premisas para un debate normativo», Revista del Instituto Español de Estudios Estratégicos, núm. 2, 2013, pp. 1-37.

9 Seline TREVISANUT, «The Principle of Non-Refoulement and the De-Territorialization of Border Control and Sea», Leiden Journal of International Law, núm. 27, 2014, pp. 661-675.

10 Jennifer HYNDMAN, Alison MOUNTZ, "Another Brick in the Wall? Neo-Refoulement and the Externalization of Asylum by Australia and Europe», vol. 43, núm. 2, 2008, pp. 249-269.

11 Katherine EISELE, The External Dimension of the EU's Migration Policy, Brill-Nijhoff, Leiden, 2014, p. 282.

12 Frank Mc NAMARA, «Member State Responsibility for Migration Control within Third States- Externalization Revisited», European Journal of Migration and Law, núm. 15, 2013, pp. 319-335, p. 326.

13 Se ha convertido en algo común referirse a las políticas migratorias como políticas «de control migratorio». El solo empleo de la expresión control migratorio hace presumir la existencia de un riesgo para la seguridad, es decir, evoca conexiones inherentes entre la seguridad y la migración, en Consejo de Derechos Humanos, Report of the Special Rapporteur on the human rights of migrants, François Crépeau, Regional Study: management of the external borders of the European Union and its impacts on the human rights of migrants, U.N.Doc. A/HRC/23/46, 24 de abril de 2013.

14 Marion JAILLARD, Philippe DE BRUYCKER et al., Setting Up the Common European Asylum System: Report on the application of existing rules and instruments for the new system, Dirección General para las Políticas Internas, Parlamento Europeo, Bruselas, 2010, p. 55.

15 Patrick VAN BERLO, «Australia’s Operation Sovereign Borders: Discourse, Power, and Policy from Crimmigration Perspective», Refugee Survey Quarterly, vol. 34, núm. 4, 2015, pp. 75-104. 
vidad para procesar allí las solicitudes de asilo o el establecimiento por Francia de una zona internacional en el aeropuerto de París constituyen ejemplos de ello ${ }^{16}$. En estos casos, el fin es alegar que el Estado no ejerce jurisdicción —ni siquiera extraterritorial - sobre el territorio dividido a estos efectos ${ }^{17}$.

A ello se añade que la externalización habitualmente va acompañada de la privatización de servicios y de sanciones a los transportistas ${ }^{18}$. Las compañías aéreas y de transporte realizan los controles en los puntos de salida e implementan decisiones de no entrada ${ }^{19}$. Para describir este fenómeno, Gammeltoft-Hansen se refiere a la «mercantilización de la soberanía», concebida como un objeto que puede ser comercializado en el mercado libre, tanto en una dimensión horizontal —entre Estados- como en una dimensión vertical —entre los Estados y los actores privados— ${ }^{20}$. Pero aún más relevante, desde una perspectiva de orden práctico, es que cuando se involucra a los actores privados resulta complicado introducir mecanismos de garantía de derechos.

La tendencia más señalada actualmente - y que presenta dudas desde el punto de vista de su falta de claridad legal e, incluso, conceptual — consiste en la adopción de los denominados «marcos de asociación en materia de migración» entre los Estados miembros de la UE o la propia UE y terceros

16 Alejandro DEL VALLE, "Control de fronteras y Unión Europea», Anuario de la Facultad de Derecho de la Facultad Autónoma de Madrid, núm. 7, 2003, pp. 67-92.

17 El TEDH estimó, con relación a este último caso, que las personas que se hallaban en la zona internacional estaban sujetas al derecho francés. A pesar de su denominación, la zona internacional no tenía estatus extraterritorial, en Amuur c. Francia, núm. 19776/92, de 25 de junio de 1996, apdo. 52.

18 Montserrat ABAD, «La participación de empresas privadas en la tramitación externa de visados: algunos problemas jurídico-internacionales en presencia, con especial énfasis en el carácter no inviolable de sus instalaciones», Revista Española de Derecho Internacional, vol. 60, núm. 2, 2008, pp. 523-538.

19 Robert McCORQUODALE, Penelope SIMONS, «Responsibility Beyond Borders: State Responsibility for Extraterritorial Violations by Corporations of International Human Rights Law», Modern Law Review, vol. 70, núm. 4, 2007, pp. 598-625; Maryellen FULLERTON, «Inadmissible in Iberia: the Face of Asylum-Seekers in Spain and Portugal», International Journal of Refugee Law, núm. 17, 2005, pp. 659-687.

20 La extraternalización se manifiesta en su dimensión horizontal en la comercialización de la soberanía y en su dimensión vertical en la privatización de las funciones de control. En Thomas GAMMELTOFT-HANSEN, Access to Asylum. International Refugee Law and the Globalisation of Migration Control, Cambridge Studies in International and Comparative Law, Cambridge, 2011, pp. 31-38. 
Estados $^{21}$. Su contenido, que no siempre se publica, tiene su base legal en lo previsto en el art. 78.2.g) TFUE, esto es, en «la asociación y cooperación con terceros países para gestionar los flujos de personas que solicitan asilo o una protección subsidiaria o temporal $»^{22}$. Su origen se remonta a los acuerdos de readmisión con terceros países que prevén la expulsión tanto de los inmigrantes irregulares como de los solicitantes de asilo cuyas peticiones hayan sido denegadas $^{23}$. Dado que este tipo de acuerdos no ha resultado todo lo efectivo que

21 Entre los acuerdos de este tipo cuyo contenido puede consultarse, por ejemplo, el Acuerdo entre el Reino de España y la República de Cabo Verde sobre vigilancia conjunta de los espacios marítimos bajo soberanía y jurisdicción de Cabo Verde, hecho en Praia, 21 de febrero de 2008 (BOE núm. 136, de 5 de junio de 2009, p. 47545). También encontramos documentos restringidos de la UE que veladamente comprometen a los terceros Estados: Joint Commission-EEAS non-paper on enhancing cooperation on migration, mobility and readmission with Afghanistan, EU Restricted, núm. 6738/16, 3 de enero de 2016, disponible en http:/www.statewatch.org/ news/2016/sep/eu-council-afghanistan-readmission-6738-16.pdf (consultado por última vez el 11.11.2016). Sobre este aspecto, y con relación a España, véase Paula GARCÍA ANDRADE, «Extraterritorial Strategies to Tackle Irregular Immigration by Sea: A Spanish Perspective», en Bernard RYAN; Valsamis MITSILEGAS (eds.), Extraterritorial Immigration Control. Legal Challenges, Martinus Nijhoff, Leiden, 2010, p. 319; y Araceli MANGAS MARTÍN, "Convenios bilaterales de España sobre inmigración con Estados Africanos», en Carlos ESPLUGUES; Guillergo PALAO; Manuel Alejandro PEREDÉS (coords.), Nuevas fronteras del Derecho de la UE: liber amicorum José Luis Iglesias Buhiges, Tirant lo Blanch, 2012, pp. 643-660. En particular, sobre los acuerdos para la admisión y protección de los trabajadores migrantes, véase Sara IGLESIAS, «Migration Agreements between the European Union and Third States», en Guy S. GOODWIN-GIL; Ph. WECKEL, Protection des migrants et des réfugiés au XXIe siècle. Aspects de droit international, Académie de Droit International de La Haye, Martinus Nijhoff, Leiden, 2015, pp. 167-193.

22 También sirven de base jurídica la Directiva 2008/115/CE del Parlamento Europeo y del Consejo de 16 de diciembre de 2008 relativa a normas y procedimientos comunes en los Estados miembros para el retorno de los nacionales de terceros países en situación irregular (DO L 348/98, de 24 de diciembre de 2008) y la Directiva 2013/32/UE del Parlamento Europeo y del Consejo de 26 de junio de 2013 sobre procedimientos comunes para la concesión o la retirada de la protección internacional (DO L 180/60, de 29 de junio de 2013) (se empleará también Directiva de Procedimiento).

23 Entre la doctrina que se refiere a los acuerdos de readmisión como ejemplo de externalización, cabe destacar: Nils COLEMAN, European Readmission Policy: Third Country Interests and Refugee Rights, Leiden, Martinus Nijhoff, 2009; Mariagiulia GIUFFRÉ, «Readmission Agreements and Refugee Rights: From a Critique to a Proposal», Refu- 
se esperaba, los Estados miembros de la UE buscan instrumentos por la vía de prácticas informales. El fin declarado es gestionar la inmigración en sentido amplio y prestar atención a las raíces del problema migratorio. Sin embargo, los marcos de asociación posibilitan también la contención de la migración, pero no ofrecen garantías a quien realmente podría valerse de protección conforme al Sistema Europeo Común de Asilo (SECA).

Precisamente, como ejemplo ilustrativo de la búsqueda de vías informales, puede citarse la Declaración UE-Turquía de 18 de marzo de 2016. El Tribunal General de la UE declaró, por medio del auto de 28 de febrero de 2017, que carecía de jurisdicción para conocer los recursos de anulación presentados contra dicha Declaración, ya que ni el Consejo Europeo ni ninguna otra institución de la UE tomó decisión alguna sobre la conclusión del acuerdo, sino que lo adoptaron los Estados miembros al margen de la organización ${ }^{24}$. Por este motivo no podía entrar a examinarlo y desestimó el recurso.

Así, los rasgos más característicos del control migratorio se han transformado no solo para los Estados miembros de la UE, sino también para los terceros Estados, que se convierten en los "guardianes» de las fronteras exteriores de la UE, y para las empresas privadas que se prestan a ello ${ }^{25}$. De este modo, se construyen fronteras virtuales en los países de origen con el fin de restringir el acceso físico a los territorios cuyos Estados podrían proveer protección ${ }^{26}$. Estas medidas desafían el clásico dictum en virtud del cual el Estado ejerce su poder

gee Survey Quarterly, vol. 32, núm. 3, 2013, pp. 79-111; y Jennifer HYNDMAN, Alison MOUNTZ, "Another Brick in the Wall? Neo-refoulment and the Externalization of Asylum by Australia and Europe», Government and Opposition, núm. 43, 2008, pp. 249 y 266.

24 Auto del Tribunal General de 28 de febrero de 2017, NF/Consejo Europeo, T-192/16, EU:T:2017:128, apdo. 73. La Declaración UE-Turquía, aprobada el 18 de marzo de 2016, fue objeto de tres recursos de anulación presentados por dos nacionales paquistaníes y un nacional afgano contra el Consejo Europeo. Los demandantes habían viajado desde Turquía a Grecia para solicitar asilo y, a la vista de la posibilidad de que fueran devueltos a Turquía en el caso de que sus solicitudes fueran rechazadas, alegaron que dicha Declaración infringía las reglas del TFUE sobre la celebración de tratados por la UE. Por su parte, el Consejo Europeo invocó la falta de jurisdicción del Tribunal para conocer el caso sobre la base del art. 263 TFUE relativo al control de la legalidad de los actos de la UE.

25 Idil ATAK y Francois CRÉPEAU, «Managing Migrations at the External Borders of the European Union: Meeting the Human Rights Challenges», Journal Européen des Droits de l'Homme, núm. 5, 2014, pp. 591-622.

26 Jennifer HYNDMAN, Alison MOUNTZ, "Another Brick in the Wall? Neo-Refoulement and the Externalization of Asylum by Australia and Europe», Government and Opposition, vol. 43, núm. 2, 2008, pp. 249-269. 
ejecutivo por sus propios funcionarios y confinado al contexto de su propio territorio ${ }^{27}$. Además, la escisión de parte del territorio y la privatización no solo restringen la aplicabilidad del derecho de los refugiados, sino que enmascaran un detrimento de los derechos humanos más allá de dicho régimen ${ }^{28}$. Lo resumió acertadamente Roldán Barbero: «La Realpolitik tiende a soslayar aspectos humanitarios y a trazar figuradamente una frontera adelantada de seguridad $»^{29}$.

Se defiende, no obstante, que este tipo de políticas responde al interés social y político por la seguridad nacional y europea; que es una forma más de preservar la prerrogativa soberana del Estado de controlar sus fronteras; que contribuye a disminuir la migración irregular y el tráfico de personas; que configura un sistema más creíble, dado que las demandas se sustancian en los países de origen que conocen las causas de la eventual persecución; y que fomenta la lógica de la negociación y de la cooperación frente a la confrontación entre los países de recepción y los países de origen ${ }^{30}$. Sin embargo, el curso de

27 Tom DE BOER, «Closing Legal Black Holes: The Role of Extraterritorial Jurisdiction in Refugee Rights Protection», Journal of Refugee Studies, vol. 21, núm. 1, 2015, pp. 118-134.

28 El afectado no puede siquiera acceder al territorio al que solicitaría protección, lo que afecta a su derecho a la libertad de circulación, recogido entre otros en el art. 13 de la Declaración Universal de los Derechos Humanos y en el art. 12 del Pacto de Derechos Civiles y Políticos. El Comité de Derechos Humanos mostró su preocupación por que las autoridades sudanesas pudieran denegar arbitrariamente los visados sin que fuera formulado ningún criterio preciso. De ahí que el Comité declarara que «toda limitación de la libertad de circulación debe estar prevista por la ley». En Comité de Derechos Humanos, Observación General 27, Libertad de Circulación (art.12), CCPR/C/21/Rev.1/Add9, 2 de noviembre de 1999, párr. 13. Véase Observaciones Finales del Comité de Derechos Humanos, Sudán, CCPR/C/79 add. 85, 19 de noviembre de 1997, párr. 14. Sobre el mismo objeto, véase Observaciones finales del Comité de Derechos Humanos, Camerún, CCPR/C/79 add. 116, 4 de noviembre de 1999, párr. 2.

29 Abundando en ello, el autor lo ilustra con un ejemplo elocuente: «Marruecos pasa como país de origen y sobre todo de tránsito, a jugar un papel determinante de frontera sur europea, dato que, entre otros, explica el estatuto avanzado concedido por la UE, el primero de este género a favor de un Estado tercero, y el hecho de que sea el país más beneficiado con los fondos de la política de vecindad para el período 2014-2017». Javier ROLDÁN BARBERO, «La aplicación territorial del derecho de la Unión Europea y el derecho internacional», Revista de Derecho Comunitario Europeo, núm. 51, 2015, pp. 453-490, p. 476.

30 Meng-Hsuan CHOU, «The European Security Agenda and the 'External Dimension' of EU Asylum and Migration Cooperation», Perspectives on European Politics and So- 
los acontecimientos no demuestra que se haya reducido la migración irregular. Al contrario, el conjunto de estas prácticas, útiles en la primera fase de su aplicación desde el punto de vista de la no entrada, pierde eficacia desde esa misma perspectiva a medio plazo. Más que contener, fuerza alternativas más cruentas. Quienes buscan asilo acuden a las redes de tráfico de personas que, a su vez, inventan nuevos medios para eludir aquellos controles ${ }^{31}$.

\section{LA DIMENSIÓN EXTERNA DE LA UNIÓN EUROPEA COMO MARCO POLÍTICO Y ESTRATÉGICO Y LOS ACUERDOS DE ASOCIACIÓN COMO OPCIÓN}

Las políticas de admisión de extranjeros en los Estados miembros de la UE en su dimensión interna, es decir, cuando estos han accedido al territorio de la UE, pueden ordenarse grosso modo de acuerdo con la distinción entre la inmigración regular, la inmigración irregular y el asilo. Los controles fronterizos y las medidas que los acompañan tienen necesariamente en cuenta esta clasificación. No todas las medidas están encaminadas a restringir la entrada, sino que traducen los intereses de los Estados y la propia UE en unos mecanismos de selección y de control. El Código de Fronteras Schengen y el SECA establecen garantías esenciales para las personas que llegan a las fronteras de los Estados miembros con el fin de solicitar asilo. Estos instrumentos prevén las condiciones de entrada, los criterios de admisión y los procedimientos de asilo y reconocimiento una vez que los solicitantes han accedido al territorio del Estado miembro o se hallan en sus fronteras ${ }^{32}$.

ciety, núm. 10, 2009, pp. 541-559. Karin DE VRIES, «An Assesment of 'Protection in Regions of Origin' in Relation to European Asylum Law», European Journal of Migration and Law, vol. 9, núm. 1, 2007, pp. 83-103. Véase también O’NIONS, op. cit., p. 178 , supra nota 6 . Véase la explicación del discurso de la externalización de ZAPATA, op. cit., supra nota 8.

31 Thomas GAMMENLTOFT-HANSEN, Sorensen NYBERG (eds.), The Migration Industry and the Commercialization of International Migration, Routledge, Oxford, 2013.

32 Directiva 2011/95/UE del Parlamento Europeo y del Consejo, de 13 de diciembre de 2011, por la que se establecen normas relativas a los requisitos para el reconocimiento de nacionales de terceros países o apátridas como beneficiarios de protección internacional, a un estatuto uniforme para los refugiados o para las personas con derecho a protección subsidiaria y al contenido de la protección concedida (DO L 337/9, de 20 de diciembre de 2011); Directiva 2013/32/UE, loc. cit., supra nota 22; y Directiva 2013/33/UE del Parlamento Europeo y del Consejo de 26 de junio de 2013 por la que se aprueban normas para la acogida de los solicitantes de protección 
El marco del presente artículo, no obstante, no es la dimensión interna de la gestión migratoria, sino la dimensión externa desarrollada por la UE. Desde la perspectiva de la evolución de esta dimensión externa, ya en 1994, cuando se exploraban las posibilidades del nuevo Tratado de la UE, que designaba las materias de asilo y la inmigración como objetivos de interés común de los Estados miembros, la Comisión Europea propuso la construcción de una política de inmigración y asilo con tres componentes: la acción sobre la presión migratoria, la acción para el control migratorio, y la acción para reforzar las políticas a favor de los inmigrantes legales. Esto implicaba prestar una especial atención a la cooperación con los países cuyos nacionales podrían emigrar a Europa ${ }^{33}$. Pero fue el Consejo Europeo de Tampere — el primero celebrado tras la entrada en vigor del Tratado de Ámsterdam - el que oficialmente perfiló el proceso para acometer las nuevas funciones externas de la UE en materia migratoria ${ }^{34}$. Las Conclusiones del Consejo Europeo de Sevilla (2002) y de Salónica (2003) añadieron nuevas pautas para integrar las políti-

internacional (DO L180/96, de 29 de junio de 2013). Cabe resaltar, no obstante, que el 13 de julio de 2016 se presentó el segundo paquete de medidas para reformar las Directivas mencionadas, propuestas recogidas respectivamente en los documentos siguientes: Comisión Europea, Proposal for a Regulation of the European Parliament and of the Council on standards for the qualification of third-country nationals or stateless persons as beneficiaries of international protection, for a uniform status for refugees or for persons eligible for subsidiary protection and for the content of the protection granted and amending Council Directive 2003/109/EC of 25 November 2003 concerning the status of third-country nationals who are long-term residents, COM (2016) 466 final, de 13 de julio de 2016; Comisión Europea, Proposal for a regulation of the European Parliament and of the Council establishing a common procedure for international protection in the Union and repealing Directive 2013/32/EU, Explanatory Memorandum, COM (2016) 467 final, de 13 de julio de 2016; y Comisión Europea, Proposal for a Directive of the European Parliament and of the Council laying down standards for the reception of applicants for international protection (recast), Explanatory Memorandum, COM (2016) 465 final, de 13 de julio de 2016.

33 Comision Europea, Communication from the Commission to the Council and the European Parliament on Immigration and Asylum Policies, COM (1994) 23 final, 23 de febrero de 1994, Preámbulo.

34 Consejo Europeo de Tampere, Conclusiones de la Presidencia, 15 y 16 de octubre de 1999, párrs. 3, 11-12 y 22-27. El Consejo se refirió a la necesidad de un control consistente de las fronteras externas para frenar la inmigración ilegal y para combatir a aquellos que la organizan. 
cas de inmigración en las relaciones de la UE con terceros Estados ${ }^{35}$. A estos los siguió el Programa de La Haya (2004), que incorporó un extenso párrafo sobre la dimensión externa del asilo y la migración y que, incluso, sugirió la viabilidad del tratamiento conjunto de las solicitudes de asilo fuera del territorio de la UE, como complemento del SECA ${ }^{36}$.

Esta finalidad se vio fortalecida con la adopción por la Comisión Europea del Enfoque Global sobre la Migración y la Movilidad (2005) cuyo objeto central era favorecer el diálogo regional y la cooperación entre los países de origen, de tránsito y de destino ${ }^{37}$. Los acuerdos de asociación con terceros países servirían de instrumento y contendrían tanto convenios de readmisión como medidas encaminadas a prestar ayuda al desarrollo, a la flexibilización temporal de la política de visados de entrada y a la lucha contra la migración irregular ${ }^{38}$.

Por todo ello, sin ánimo de entrar en el análisis sobre la evolución de la dimensión externa de la política migratoria de la UE, amplia y profundamente estudiada por la doctrina ${ }^{39}$, basta con recordar aquí que el Consejo Euro-

35 Consejo Europeo de Sevilla, Conclusiones de la Presidencia, 21 y 22 de junio, párrs. 33-36 y Consejo Europeo de Salónica, Conclusiones de la Presidencia, 19 y 20 de junio de 2003, párrs. 9-23.

36 Consejo Europeo de Bruselas, Conclusiones de la Presidencia, 4 y 5 de noviembre de 2004, Anexo I: El Programa de La Haya, Consolidación de la libertad, la seguridad y la justicia en la Unión Europea, párrs. 1.3 y 1.6.

37 Comisión Europea, Comunicación de la Comisión al Consejo y al Parlamento Europeo, Medidas prioritarias para afrontar los retos de la inmigración: primera etapa del proceso de seguimiento de Hampton Court, COM (2005) 621 final, 30 de noviembre de 2005.

38 Javier GONZÁLEZ VEGA, «El control de la inmigración irregular en España. Compromisos y desarrollos», Revista CIDOB d'Afers Internacionals, núm. 11, 2015, pp. 173-193; y Alejandro DEL VALLE, «Unión Europea, Crisis de Refugiados y 'Limes Imperii'», Revista General de Derecho Europeo, núm. 38, 2016, pp. 1-13.

39 Paula GARCÍA ANDRADE, La acción exterior de la Unión Europea en materia migratoria, Tirant lo Blanch, Valencia, 2015; Javier GONZÁLEZ VEGA, "¿Regreso al futuro? La política de inmigración en la Unión Europea», en Francisco ALDECOA (dir.), Los Tratados de Roma en su cincuenta aniversario, Marcial Pons, Madrid, 2008, pp. 1561-1578; Sara IGLESIAS, «Migration Agreements between the European Union and Third States», en GOODWIN-GILL; WECKEL, op.cit., pp. 167-194, supra nota 21; Sandra LAVENEX, «EU 'External Governance' in Wider Europe», Journal of European Public Policy, vol. 11, núm. 1, 2004, pp. 680-700; José MARTÍN Y PÉREZ DE NANCLARES (coord.), La dimensión exterior del Espacio de Libertad, Seguridad y Justicia de la UE: en busca de una acción de la UE eficaz, coherente y coordinada, Iustel, Madrid, 2012; Carmen PÉREZ GONZÁLEZ, 
peo de Tampere sentó las bases del enfoque llamado «global» en el ámbito migratorio ${ }^{40}$. Esta globalidad lleva consigo abordar las causas de la migración en su origen y atender literalmente a los «problemas políticos, de derechos humanos y de desarrollo de los países y regiones de origen y de tránsito» con la finalidad última de hacer disminuir los flujos migratorios y de promover el retorno voluntario ${ }^{41}$. Sobre estas bases, los primeros acuerdos de cooperación y asociación con terceros países incluyeron cláusulas sobre la normalización de los flujos migratorios y medidas para abordar la inmigración ilegal $^{42}$. Esta dimensión inicialmente se limitaba a la celebración de acuerdos de readmisión ${ }^{43}$. La competencia de la UE para adoptar medidas de repatriación le era explícitamente conferida mediante el art. 63 (3) del TCE, que fue

Migraciones irregulares y Derecho Internacional, Tirant lo Banch, Valencia, 2012; y Daniel THYM y Margarite ZOETEWEIJ-TURHAM, Rights of Third-Country Nationals under EU Association Agreements. Degrees of Free Movement and Citizenship, Brill-Nijhoff, Leiden, 2016.

40 Consejo Europeo de Tampere, op.cit., supra nota 34.

41 Cristina GORTÁZAR ROTAECHE, «El enfoque global de la migración en la UE y el derecho humano al desarrollo», Miscelánea Comillas, vol. 67, núm. 130, 2009, pp. 199-216.

42 Acuerdo de Asociación entre los Estados de África, del Caribe y del Pacífico y la CE, firmado en Cotonú el 23 de julio de 2000, modificado el 25 de junio de 2005 (DO L 209 , de 11 de agosto de 2005, p. 27) y por segunda vez el 22 de junio de 2010 (DO L 287, de 4 de noviembre de 2010, p. 3).

43 Nuria ARENAS HIDALGO, «El acuerdo de readmisión de inmigrantes en situación irregular con Pakistán. Punto de inflexión o huida hacia delante», Revista General de Derecho Europeo, núm. 24, 2011, pp. 1-40; Anneliese BALDCCINI, «The External Dimension of the EU's Asylum and Immigration Policies: Old Concerns and New Approaches», en Anneliese BALDACCINI; Elspeth GUILD; Helen TONER (eds.), Whose Freedom, Security and Justice? EU Immigration and Asylum Law and Policy, Hart Publishing, Oxford, 2007, pp. 276-298; Purdey DE VISSCHER, «Legal Migration in the Relationship between the European Union and ACP Countries: The Absence of a True Global Approach Continues», European of Journal and Migration and Law, vol. 13, núm. 1, 2011, pp. 53-94; James HAMPSHIRE, «Speaking with One Voice? The European Union's Global Approach to Migration and Mobility and the Limits of International Migration Cooperation», Journal of Ethnic and Migration Studies, vol. 42, núm. 4, 2015, pp. 571-586; Sandra LAVENEX, «Multilevelling EU external governance: The Role of International Organizations in the Diffusion of EU Migration Policies», Journal of Ethnic and Migration Studies, vol. 42, núm. 4, 2016, pp. 554-570; y Jorrit RIJPMA, Marise CREMONA, "The Extra-Territorialisation of EU Migration Policies and the Rule of Law», EUI Working Papers LAW, Instituto Universitario Europeo, Florencia, 2007. 
reemplazado por el art. 79 (3) TFUE que prevé la competencia específica para concluir acuerdos de readmisión con terceros países ${ }^{44}$.

La dimensión externa de la política de asilo e inmigración de la UE es, no obstante, mucho más amplia en su alcance que los aspectos relacionados con el retorno y la readmisión. Fomenta la cooperación con terceros países al servicio de dos objetivos: organizar la migración legal y controlar la migración ilegal ${ }^{45}$. En ambos casos, el fin es implicar a los países de origen y de tránsito. El alcance inclusivo de la dimensión externa se refleja también en el TFUE, ya que ofrece unas bases legales más expresas para la acción exterior asociadas a la migración y al asilo si se compara con el antiguo TCE. El TFUE prevé en concreto la instauración de un sistema integrado de gestión de fronteras exteriores, la asociación y la cooperación con terceros países para gestionar los flujos de personas que solicitan asilo o una protección subsidiaria o temporal y la prevención de la inmigración ilegal ${ }^{46}$.

La Comisión Europea mantiene esta misma línea en la Agenda Europea de la Migración de 2015, que asigna al Servicio Europeo de Acción Exterior y a la propia Comisión la función de colaborar con los países asociados y adoptar medidas concretas, entre ellas la implementación de los programas regionales de desarrollo ${ }^{47}$. Como ejemplo, la Agenda de 2015 contiene la propuesta de crear en Níger un centro polivalente en colaboración con la Organización Internacional para las Migraciones y el ACNUR. La finalidad del centro es prestar protección a nivel local y ofrecer oportunidades de reasentamiento a las personas que lo necesiten ${ }^{48}$. A su vez, la migración se convierte en un componente específico de las misiones en curso en el marco de la Política Común de Seguridad y Defensa en países como Níger y Mali, que se reforzarán en lo

44 Sobre las dificultades para la calificación de determinados tipos de acuerdos, véase Paz ANDRÉS SÁENZ DE SANTA MARÍA, «La Unión Europea y el Derecho de los Tratados: una relación compleja», Revista Española de Derecho Internacional, vol. 68, núm. 2, 2016, pp. 51-102, en concreto pp. 86-88. DEN HEIJER, op.cit., p. 171, supra nota 7.

46 Arts. 77 (1) (c), 77 (2) (d), 78 (2) (g) y 79 (1) TFUE. También cabe aludir, como medio para prevenir los flujos migratorios, a la cooperación para el desarrollo contemplada en los arts. 208-211 TFUE, dentro del título relativo a la «Acción exterior de la UE».

47 Comisión Europea, Agenda Europea para la Migración, COM (2015) 240 final, 13 de mayo de 2015. La Agenda pone el acento en cuatro aspectos principales: la lucha contra la inmigración irregular; la gestión de las fronteras con el objetivo de salvar vidas; la garantía plena y coherente del SECA; y la revisión de las políticas de integración en la UE (para lo que sería necesaria una política común de inmigración).

Ibid., p. 6. 
que respecta a la gestión de las fronteras ${ }^{49}$. Así las cosas, el Nuevo Marco de Asociación de 2016 representa la materialización de los objetivos previstos en la Agenda, su ejecución se ha iniciado ya en cinco países (Nigeria, Níger, Senegal, Mali y Etiopía), en los que se avanza en medidas sobre la lucha contra el tráfico de migrantes, la negociación de acuerdos de readmisión y el fomento del diálogo con la UE y los Estados miembros ${ }^{50}$.

Por otro lado, una de las respuestas más visibles, presentada por la Comisión Europea ante la llamada crisis de los refugiados acontecida entre 2013 y 2016 en el Mediterráneo, fue la renovación del mandato y las competencias de la agencia Frontex. A los efectos de la cooperación con terceros países, el Reglamento de 14 de septiembre de 2016 prevé que Frontex «deberá facilitar la cooperación técnica y operativa entre los Estados miembros y terceros países en el marco de la política de relaciones exteriores de la Unión, también en lo relativo a la protección de los derechos fundamentales y el principio de no devolución» ${ }^{51}$. El Reglamento de 2016 vincula toda actividad de la Agencia con el cumplimiento de dichos derechos y el mencionado principio, incluso cuando actúa en el territorio de terceros países. Sin embargo, más allá de la referencia a países terceros, llama la atención la ausencia de una mención expresa en el nuevo Reglamento al concepto de jurisdicción conectado con los ámbitos de aplicación territoriales o marítimos y la limitada referencia al alcance del art. 51 (1) CDFUE en el contexto de las operaciones de Frontex. Cabe tan solo recordar el recurso de anulación interpuesto por el Parlamento Europeo ante el TJUE sobre la legalidad de las directrices para las operaciones marítimas de Frontex (Decisión 2010/252/UE del Consejo, de 26 de abril de 2010), que completaba el Código de Fronteras Schengen en lo referente a la

49 Ibid., p. 7.

50 Comisión Europea, Communication from the Commission to the European Parliament, the European Council, the Council and the European Investment Bank on establishing a new Partnership Framework with third countries under the European Agenda on Migration, COM (2016) 385 final, 7 de junio de 2016. El primer informe sobre su aplicación se puede consultar en Comisión Europea, Communication from the Commission to the European Parliament, the European Council and the Council, First Progress Report on the Partnership Framework with third countries under the European Agenda on Migration, COM (2016) 700 final, 18 de octubre de 2016.

51 Art. 54 del Reglamento (UE) 2016/1624 del Parlamento Europeo y del Consejo de 14 de septiembre de 2016 sobre la Guardia Europea de Fronteras y Costas, por el que se modifica el Reglamento (UE) 2016/399 del Parlamento Europeo y del Consejo y por el que se derogan el Reglamento (CE) núm. 863/2007 del Parlamento Europeo y del Consejo, el Reglamento (CE) núm. 2007/2004 del Consejo y la Decisión 2005/267/CE del Consejo (DO L 251/1, de 16 de septiembre de 2016). 
vigilancia de fronteras marítimas. Precisamente, uno de los motivos alegados por el Parlamento Europeo en su recurso era que el ámbito de aplicación de la Decisión impugnada no se ajustaba al ámbito de aplicación territorial del Código de Fronteras Schengen. Este se refería a la vigilancia en los pasos fronterizos y en cambio, la Decisión se extendía no solo a las aguas territoriales, sino también a las zonas contiguas y al alta mar. El elemento de la vigilancia exterior fue decisivo para que el TJUE determinara que se trataba de decisiones políticas que debían adoptarse por el procedimiento legislativo ordinario, un cauce que no se había seguido y que conllevaba la anulación de la Decisión $^{52}$. Solo por este motivo, el Reglamento de 2016 relativo a las competencias de Frontex podía haber profundizado en los criterios sobre la conexión normativa de los actos de los Estados con la CDFUE cuando desarrolla sus competencias en el exterior.

Todo ello representa la mutación del alcance de la legislación europea y de sus políticas, que transitan desde las propias fronteras de la UE hacia los terceros países. Precisamente, la dimensión externa del control migratorio es el marco que sirve de base para el desarrollo de las medidas de externalización. Este es el referente político y jurídico que las explica y las permite, pero que no aclara el impacto que puede tener en el principio de non-refoulement.

\section{EL NON-REFOULEMENT Y SU ÁMBITO DE APLICACIÓN RATIONE LOCI}

\section{LOS LÍMITES DEL PRINCIPIO DE NON-REFOULEMENT}

Antes de entrar a considerar los aspectos centrales del presente estudio, merece la pena aludir a una aclaración de orden terminológico que, por conocida que sea, guarda una importancia fundamental para entender el sentido del presente análisis. Nos referimos al significado de refugio derivado de la CG sobre el Estatuto de los Refugiados de 1951 y de su Protocolo de $1967^{53}$. Dicha CG es el primer gran tratado internacional elaborado para dar respuesta inmediata y específica a un problema propiamente europeo, provocado por la aparición de nuevos regímenes políticos y por los desplazamientos de

52 Sentencia del TJUE (Gran Sala), de 5 de septiembre de 2012, Parlamento Europeo/ Consejo, C-355/10, EU:C:2012:516, apdos. 63-85.

53 Todos los Estados miembros de la UE son parte en la CG de 1951 y en el Protocolo de 1967. 
población que ocasionó el fin de la Segunda Guerra Mundial. De acuerdo con la definición de la CG, es refugiado quien «debido a fundados temores de ser perseguido por motivos de raza, religión, nacionalidad, pertenencia a determinado grupo social u opiniones políticas, se encuentra fuera del pais de su nacionalidad y no pueda o, a causa de dichos temores, no quiera acogerse a la protección de tal país». Además del concepto de refugiado, el art. 33 CG alumbra el principio de non-refoulement, que preside el sistema del refugio y prohíbe a los Estados parte "por expulsión o devolución, poner en modo alguno a un refugiado en las fronteras de los territorios donde su vida o su libertad peligre por causa de su raza, religión, nacionalidad, pertenencia a determinado grupo social, o de sus opiniones políticas" ${ }^{54}$.

El problema reside en que el non-refoulement únicamente se activa para las personas reconocidas como refugiadas conforme al art. 1 CG. Este planteamiento reviste especial importancia porque refleja una limitación del principio: solo los refugiados fisicamente presentes en el Estado de recepción (o en sus fronteras) hacen nacer la obligación de no devolución. Cuando los Estados contienen y controlan los flujos migratorios que aún no han llegado a sus territorios o zonas fronterizas, ¿en qué medida siguen siendo responsables bajo el ordenamiento internacional en lo que se refiere a la no devolución?

Mientras que el principio de non-refoulement es la piedra angular de la CG; en el CEDH, el principio es operativo por la vía de la prohibición de la tortura y de otros tratos inhumanos o degradantes, sin que figure recogido de manera expresa. El principio de non-refoulement opera en un contexto de «asilo» para amparar a las personas bajo la jurisdicción de los Estados miembros del CEDH que buscan protección internacional frente a la tortura y los tratos

54 Art. 33 (1) CG. Cursiva añadida. También recogen el principio de non-refoulement los siguientes instrumentos jurídicos: en el ámbito universal, el art. 16 (1) de la Convención de las Naciones Unidas sobre la Protección de las Desapariciones Forzosas; en los ámbitos regionales, el art. 2 (2) de la Convención de la Unión Africana sobre los Aspectos Específicos de los Problemas de los Refugiados en África de 1969, el art. 12 (3) de la Carta Africana de Derechos Humanos y de los Pueblos de 1981, el art. 22 (8) de la Convención Americana de los Derechos Humanos de 1969 y el art. 13 (4) de la Convención Interamericana para Prevenir y Sancionar la Tortura. En cuanto al derecho derivado de la UE, cabe remitirse, entre la numerosa normativa, a la Directiva 2013/32/UE, loc. cit., supra nota 22, y al Reglamento 2016/1624 del Parlamento Europeo y del Consejo, de 15 de septiembre de 2016, sobre la Guardia Europea de Fronteras y Costas, por el que se modifica el Reglamento UE (CE) núm. 863/2007 del Parlamento Europeo y del Consejo, el Reglamento (CE) 2007/2004 del Consejo y la Decisión 2005/267/CE del Consejo (DO L 251/1, de 16 de septiembre de 2016). 
inhumanos o degradantes. El CEDH no protege ni expresa ni exclusivamente a los refugiados de la CG, sino a aquellos que podrían «refugiarse» en su art. 3 .

En el derecho de la UE, como es sabido, la comunitarización del derecho de asilo tiene lugar a través del Tratado de Ámsterdam, que establece por primera vez las bases legales para su armonización y por la vía del derecho derivado posterior. A ello se añade el art.19 (2) CDFUE que prohíbe la devolución, expulsión o extradición a un Estado en el que el afectado corra un grave riesgo de ser sometido a la pena de muerte, a tortura o a otras penas o tratos inhumanos o degradantes, términos coincidentes con el art. $3 \mathrm{CEDH}$.

La centralidad del non-refoulement en el acervo comunitario y las similitudes entre la jurisprudencia de Estrasburgo y de Luxemburgo cada vez se hacen más patentes. La Sentencia $N$. S. y M. E. del TJUE representa el punto de partida en este sentido, ya que considera equivalentes "las deficiencias sistémicas» existentes en los Estados miembros responsables de examinar una solicitud de asilo conforme al Reglamento Dublín II y el «riesgo real» empleado por el TEDH con relación al art.3 CEDH, lo que llevó al Tribunal de Luxemburgo a aplicar el art.4 CDFUE ${ }^{55}$. Incluso, en la Sentencia Aranyosi y Caldaruru, el TJUE reafirmó el "carácter absoluto» del derecho garantizado por la CDFUE en su art. 4 y manifestó expresamente que «está corroborado por el art. 3 del $\mathrm{CEDH}^{56}{ }^{5}$. Sin embargo, no siempre coinciden los estándares declarados por el TEDH con el acervo comunitario. Como ejemplo, la jurisprudencia del TEDH admite el efecto suspensivo de la demanda de protección internacional, mientras que por el contrario, la Directiva de Procedimiento no reconoce dicho efecto suspensivo en el caso de que el solicitante impugne la aplicación del concepto de tercer país seguro. Aún más, este concepto parece consolidarse en la futura reforma, al igual que la llamada «protección interna alternativa» que también presenta características de dudoso ajuste con el principio de non-refoulement. En la medida en que el art. 52 (3) CDFUE confiere un «sentido y alcance» equivalente a los derechos contenidos en la CDFUE y en el $\mathrm{CEDH}$, cabe esperar que los desarrollos jurisprudenciales del Tribunal de Estrasburgo se tengan presentes en el ámbito legislativo y judicial de la $\mathrm{UE}^{57}$. Es más, el mismo art. 52 (3) CDFUE in fine prevé que este no es obs-

55 Sentencia de 21 de diciembre de 2011, N. S. y M. E., C-411-10 y C-493/10, EU:C: 2011:865.

56 Sentencia de 5 de abril de 2016, Aranyosi y Caldaruru, C-404/15 y C-659/15 PPU, apartados 86 y 87 .

57 El propio TJUE se muestra favorable a tener en cuenta la jurisprudencia del TEDH. La Sentencia $J . M c B$ y L. E. sobre el derecho de custodia declaró que "conforme al art. 52.3 de la Carta, debe darse al art. 7 (de la Carta) el mismo sentido y el mismo alcance que los conferidos al art. 8 (1) del CEDH, tal como lo interpreta la jurispru- 
táculo para que «el derecho de la Unión conceda una protección más extensa». En palabras del abogado general Mengozzi: «Il s'ensuit que le niveau de protection assurée para la CEDH ne constitue qu'un seuil minimal, en deçà duquel l'Union ne saurait descendre, l'Union pouvant, en revanche donner aux droits garantis para la Charte qui correspondent à ceux de la $\mathrm{CEDH}$ une portée plus large» ${ }^{58}$.

\section{2. ÁMBITO DE APLICACIÓN TERRITORIAL: ANTECEDENTES EN EL DERECHO COMPARADO}

La laguna de la CG en lo que se refiere a su ámbito de aplicación ratione loci invita a hacer interpretaciones tanto restrictivas como abiertas respecto de su alcance geográfico ${ }^{59}$. La cuestión es dilucidar si el solicitante debe encontrarse en el territorio del Estado de recepción para beneficiarse del principio de non-refoulement o si podría invocarlo también en otras situaciones que, aunque carezcan de vinculación física con el territorio, implican el ejercicio de la jurisdicción por el Estado de destino.

Para empezar, el non-refoulement ampara tanto a aquellos que se hallan dentro del territorio del Estado de destino como a quienes se encuentran en sus fronteras, entendidas estas como espacios territoriales bajo su competen$\mathrm{cia}^{60}$. La jurisdicción es principalmente territorial y, por tanto, es indiscutible que el individuo que se halla en el territorio del Estado queda sometido a su

dencia del TEDH» en Sentencia de 5 de octubre de 2010, J. McB. y L. E., C-400/10, EU:C:2010, 582, apdo. 52.

58 Conclusiones del abogado general Mengozzi, presentadas en el asunto X C-638/16 PPU, EU:C:2017:93, punto 99.

59 El art. 40 CG contiene una cláusula llamada «colonial» que permite a los Estados extender su aplicación a los territorios que no puedan formar parte del tratado por no haber obtenido personalidad jurídica internacional. No obstante, no se trata, realmente, de un precepto relativo al ámbito de aplicación territorial de la Convención. Véase María Teresa GIL BAZO, «Art. 40. 1951 Convention (Territorial Application Clause)», en Andreas ZIMMERMANN (ed.), The 1951 Convention Relating the Status of Refugees. A Commentary, Oxford University Press, Oxford, 2011, pp. 15671588.

60 Elihu LAUTERPACHT, Daniel BETHLEHEM, «The Scope and Content of the Principle of Non-Refoulement: Opinion», en Erika FELLER; Volker TÜRK; Frances NICHOLSON (eds.), Refugee Protection in International Law: UNHCR's Global Consultations on International Protection, Cambridge University Press, Cambridge, 2003, pp. 87, 113-115. 
jurisdicción, haya entrado en él legalmente o bajo cualquier otra circunstan$\mathrm{cia}^{61}$. Hasta aquí no se plantean problemas sobre su aplicación territorial.

En el marco del derecho comparado, los dilemas en torno al alcance geográfico del non-refoulement se suscitaron por primera vez en el ámbito judicial ante el Tribunal Supremo estadounidense en el caso Sale c. Haitian Centers Council $^{62}$. Tras los sucesos provocados por el derrocamiento del presidente Aristide en Haití, el entonces presidente estadounidense George H. W. Bush adoptó una Orden Ejecutiva en la que requería a los guardacostas estadounidenses que interceptaran, en aguas internacionales, las embarcaciones que transportaran pasajeros procedentes de Haití con dirección a Estados Unidos y que las enviaran de nuevo a dicho país ${ }^{63}$. Conforme a la Orden, el principio de no devolución solo era aplicable a las personas que se hallaran dentro del territorio estadounidense ${ }^{64}$. El Tribunal Supremo apoyó por mayoría la decisión del Gobierno estadounidense sobre la base de la lectura literal del art. 33 (1) CG y explicó que este precepto remite al acto defensivo, de resistencia o exclusión que ocurre en la frontera y no al acto de trasladar a alguien a un destino particular ${ }^{65}$. Incluso, el Tribunal Supremo afirmó que de un tratado no se pueden deducir obligaciones extraterritoriales no contempladas expresamente, más allá de su intención humanitaria general ${ }^{66}$.

Desde la perspectiva del Tribunal Supremo estadounidense, la obligación de no devolución únicamente surge una vez que la persona ha entrado en el territorio del Estado. En contra de esta lectura, el juez Blackmun, en su opinión

61 TEDH, Louzidou c. Turquí (Objeciones Preliminares), núm. 15318/89, 23 de marzo de 1995, apdo. 62; TEDH, Issa y otros c. Turquía, núm. 31821/96, 16 de noviembre de 2004, apdo. 71; TEDH, Al-Skeini y otros c. Reino Unido, núm. 55721/07, 7 de julio de 2011, apdo. 131; TEDH, (Gran Sala) Hirsi Jamaa y otros c. Italia, núm. 27765/09, 23 de febrero de 2012, apdo. 73.

62 Sentencia del Tribunal Supremo de los Estados Unidos, Sale c. Haitian Centers Council, Inc., 509 US 155, 21 de junio de 1993.

63 Executive Order 12807, Interdiction of Illegal Aliens, 24 de mayo de 1992 (Federal Register, vol. 57, núm. 105, 1 de junio de 1992, pp. 23133-23134).

64 Ibid., apdo. 2 (cursiva añadida).

65 Sentencia del Tribunal Supremo de los Estados Unidos, Sale c. Haitian Center, loc. cit., apdo. 182, supra nota 62.

66 En palabras del Tribunal Supremo estadounidense: «The drafters of the Convention of 1951 and the parties to the Protocol of 1967 may not have contemplated that any nation would gather fleeing refugees and return them to the one country they had desperately sought to escape; such actions may even violate the spirit of Article 33; but a treaty cannot impose uncontemplated extraterritorial obligations on those who ratify it through no more than its general humanitarian intent» (cursiva añadida), ibid., p. 2. 
disidente, estimó que el art. 33.1 CG tan solo indica el lugar al que el refugiado no puede ser enviado, pero no contiene limitación alguna respecto del lugar desde donde puede ser expulsado ${ }^{67}$. Aún más, el juez añadió que, hasta que el litigio tuvo lugar, el Gobierno estadounidense había asumido de manera consistente que la CG se aplicaba en alta mar. Posteriormente, tanto la Comisión Interamericana de Derechos Humanos ${ }^{68}$ como el ACNUR $^{69}$ declararon que la Orden Ejecutiva del Gobierno estadounidense infringía el art. 33 CG.

Once años después, en el caso Regina c. Immigration Officer ocurrido en el aeropuerto de Praga, la Cámara de los Lores se apoyó de manera expresa en la Sentencia Sale c. Haitian Centers Council. Sin embargo, el llamado "caso del aeropuerto de Praga» tiene un elemento muy relevante que lo distingue de Sale: los puestos de inmigración británicos se ubicaban en territorio checo, en concreto en el aeropuerto de Praga, y los solicitantes de asilo se encontraban en dicho territorio, esto es, aún en su país de origen. Dado que los afectados no habían salido de su territorio, la Cámara de los Lores estimó que no era aplicable la CG. No existía norma alguna que concediera a los individuos que desearan salir de su país en busca de asilo, pero que aún se hallaran en dicho país, el derecho a que su solicitud fuera examinada. No entraban, por tanto, dentro de la definición de refugiado del art. 1 a (2) CG. Tampoco podían asimilarse los puestos de inmigración británicos ubicados en el aeropuerto checo a sus fronteras exteriores salvo en un sentido «altamente metafórico» ${ }^{70}$. La Cámara de los Lores sostuvo que el art. 33 (1) CG no era aplicable. Lord Bingham manifestó con rotundidad que dicho precepto no tiene efectos extraterritoriales. Sus palabras merecen ser citadas in extenso:

67 Concretamente, estima el Tribunal Supremo: «Article 33.1 is clear not only in what it says, but also in what it does not say: it does not include any geographical limitation. It limits only where a refugee may be sent 'to', not where he may be sent from», Ibid., p. 2 (cursiva añadida).

68 Comisión Interamericana de Derechos Humanos, Report 51/96, Decision of the Commission as to the merits of case 10 675, (Haitian Interdiction case), 3 de marzo de 1997, apdo. 156-58.

69 ACNUR, Opinión Consultiva sobre la aplicación extraterritorial de las obligaciones de no devolución en virtud de la Convención sobre el Estatuto de los Refugiados de 1951 y su Protocolo de 1967, 26 de enero de 2007, disponible en: http://www. refworld.org/docid/45f17a1a4.html (consultado por última vez el 6.11.2016).

70 Cámara de los Lores, Regina v. Immigration Officer at Prague Airport and another (Respondents) ex parte European Roma Rights Centre and others (Appellants), 9 de diciembre de 2004, apdo. 26 (en concreto, en palabras de lord Bingham de Cornhill). 
[...] the Convention was exclusively directed to those who are "outside the country» of their nationality [...] The Convention is directed towards those who are within the receiving state [...] The French verb refouler and the French noun refoulement are, in article 33, the subject of a stipulative definition: they must be understood as having the meaning of the English version and noun «return» ${ }^{71}$.

A modo de recapitulación, en ninguno de los dos casos citados se aplica lo acordado en la CG porque los órganos judiciales adoptan una postura exclusivamente territorialista: ni los buques haitianos se hallaban en territorio estadounidense, ni los probables refugiados checos se hallaban en territorio británico.

Como adelantábamos en las páginas precedentes, es en este marco donde encuentra las grandes limitaciones la garantía del non-refoulement. ¿Constituye una conditio sine qua non que el solicitante se encuentre físicamente en el territorio del país de destino para que pueda apelar al non-refoulement? En esta línea, subrayando que se trataría de una solución insatisfactoria, Robinson critica que el art. 33 CG ampare a «los refugiados que han entrado en el territorio del Estado, legal o ilegalmente, pero no a los refugiados que solicitan la entrada en dicho territorio. En otras palabras, si el refugiado ha logrado eludir a los guardias fronterizos, está a salvo; si no lo ha conseguido, entonces ha tenido mala suerte» ${ }^{72}$. En efecto, si esta fuera la interpretación válida, entonces la protección que otorga la CG se centraría en la habilidad del refugiado para acceder clandestinamente al país de asilo y no en la necesidad de protección internacional de la persona ${ }^{73}$.

Por otro lado, la normativa del SECA —o el acervo comunitario en materia de asilo- fue expresamente concebido con una vocación puramente territorial, ya que el conjunto de las directivas y reglamentos que lo componen aluden a las normas de procedimiento y recepción dentro de los Estados miembros para conceder o retirar la protección internacional. Stricto sensu, no podrían acogerse a este régimen las solicitudes presentadas fuera del territorio de los Estados miembros. Entre otros instrumentos, el Reglamento Dublín III se aplica solo a las peticiones presentadas en uno de los Estados miembros, lo

71 Ibid., apdo. 15.

72 Nehemiah ROBINSON, Convention Relating to the Status of Refugees: Its History, Contents and Interpretation. A Commentary, Institute for Jewish Affairs, Nueva York, 1953, p. 163.

73 Sentencia del Tribunal Supremo de los Estados Unidos, Sale c. Haitian Centers, loc. cit., p. 92, supra nota 62. 
que incluye en sus fronteras ${ }^{74}$. La Directiva de Procedimiento dispone que esta se aplicará «a todas las solicitudes de protección internacional presentadas en el territorio, con inclusión de la frontera, en las aguas territoriales o en las zonas de tránsito de los Estados miembros» ${ }^{75}$. La misma Directiva, expresamente, excluye de su ámbito de aplicación las solicitudes presentadas en las representaciones consulares o diplomáticas de los Estados miembros ${ }^{76}$. El único instrumento que no contiene una restricción territorial explícita es la Directiva de Reconocimiento ${ }^{77}$. Esta ausencia se explica porque, en el momento de la redacción del texto, los Estados miembros decidieron que el ámbito de aplicación de la Directiva tendría que ser consistente con la futura Directiva de Procedimiento. Ahora bien, el hecho de que no contenga mención alguna a su ámbito de aplicación no lleva a concluir que su alcance sea extraterritorial ${ }^{78}$. De modo que, tal y como está contemplado en el SECA, difícilmente podría emplearse el principio de no devolución allí contenido para alegar su proyección extraterritorial. Dicho acervo comunitario sobre el asilo no dispone de instrumentos específicos que regulen el estatus de los refugiados en el ámbito del control migratorio externo. Así las cosas, la cuestión de los derechos de los refugiados que caen bajo el ámbito de la dimensión externa de la UE dependerá del alcance que se conceda a los arts. 18 y 19 CDFUE, cuyo contenido debe corresponderse a su vez con el de la CG y con los derechos garantizados en el CEDH. A este respecto, son elocuentes las palabras del abogado general Mengozzi en el marco de una cuestión prejudicial presentada ante el TJUE. Esta procede del litigio entre dos nacionales sirios y sus tres hijos, residentes en la ciudad de Alepo (Siria) y Bélgica. El Estado belga se niega a otorgarles un visado de validez territorial limitada solicitado por razones humanitarias ante la embajada belga en Beirut. Ante las alegaciones del gobierno belga, que

74 Reglamento (UE) núm. 604/2013 del Parlamento Europeo y del Consejo, de 26 de junio de 2013, por el que se establecen los criterios y mecanismos de determinación del Estado miembro responsable del examen de una solicitud de protección internacional presentada en uno de los Estados miembros por un nacional de un tercer país o una apátrida (DO L 180/31, de 29 de junio de 2013).

75 Cursiva añadida.

76 Art. 3 de la Directiva de Procedimiento, loc. cit., supra nota 22.

77 Directiva 2011/95/UE del Parlamento Europeo y del Consejo, de 13 de diciembre de 2011, por la que se establecen normas relativas a los requisitos para el reconocimiento de nacionales de terceros países o apátridas como beneficiarios de protección internacional, a un estatuto uniforme para los refugiados o para las personas con derecho a protección subsidiaria y al contenido de la protección concedida (DO L 337/9, de 20 de diciembre de 2011).

78 DEN HEIJER, op. cit., pp. 204-205, supra nota 7. 
defiende que los puestos diplomáticos no forman parte de las autoridades ante las que un extranjero puede presentar una demanda de asilo, el abogado general descarta todo criterio territorial en los siguientes términos: «Il convient encore de souligner que les droits fondamentaux reconnus par la Charte, dont le respect s'impose à tout autorité des État membres agissant dans le cadre du droit de l'Union, sont garantis au destinataires des actes adoptés par un telle autorité indépendamment de tout critère de territorialités ${ }^{79}$.

De acuerdo con el abogado general, los Estados miembros deberán dispensar visados humanitarios cuando existan motivos para creer que los solicitantes de protección se expondrían al peligro de ser víctimas de torturas o de tratamientos inhumanos o degradantes en su país de origen. Fundamenta su argumentación sobre la base del art. 51(1) CDFUE que prevé que esta se dirige a los Estados miembros cuando apliquen el derecho de la UE, en este caso, el Código de Visados, al margen de criterios territoriales o extraterritoriales ${ }^{80}$.

Por otro lado, el art. 78 TFUE, que establece las competencias de la UE para desarrollar una política común de asilo, omite la referencia que el anterior art. 63 TCE hacía al describir las condiciones de recepción «en los Estados miembros». Incluso, el nuevo art. 78 TFUE añade un párrafo relativo a «la asociación y la cooperación con terceros países para gestionar los flujos de personas que solicitan asilo o una protección subsidiaria o temporal». Por todo ello, la competencia territorial de los Estados miembros se revela insuficiente y el desarrollo de criterios alternativos aparece justificado.

\section{3. ÁMBITO DE APLICACIÓN EXTRATERRITORIAL: ALGUNOS CRITERIOS JURISPRUDENCIALES DEL TEDH Y DEL TJUE}

Pese a que la CG no se pronuncia sobre la aplicación extraterritorial del art. $33 \mathrm{CG}$, este establece dos prohibiciones que ayudan a explicar su alcance: una relativa a la expulsión y otra relativa a la devolución. La expulsión claramente se refiere a las acciones que tienen lugar desde un Estado parte; la devolución, sin embargo, prohíbe las acciones que ponen al refugiado en las fronteras de los territorios cuya vida o libertad está amenazada, pero no necesariamente desde el territorio del Estado parte. En esta línea, Lauterpacht afirma que «la obligación del art. 33 CG no está sujeta a restricciones

79 Conclusiones del abogado general Mengozzi, loc.cit., punto 89, supra nota 5.

80 Reglamento (CE) núm. 810/2009 del Parlamento Europeo y del Consejo, de 13 de julio de 2009, por el que se establece un Código Comunitario sobre Visados (Código de Visados) (DO L 243/1, de 15 de septiembre de 2009). 
territoriales, se aplica cualquiera que sea el lugar en el que el Estado en cuestión ejerce jurisdicción» ${ }^{81}$.

A esto se añade que el art. $33 \mathrm{CG}$ prohíbe devolver a los refugiados «en modo alguno" a los territorios donde pueden ser perseguidos ${ }^{82}$. Se recoge la expresión «devolver en modo alguno a un refugiado» para prohibir cualquier acto de devolución que pudiera poner al individuo en riesgo. Por lo tanto, el art. 33 CG incluye el rechazo en frontera, en las zonas en tránsito y en alta mar. Es más, otras políticas de no entrada tienen cabida en esta interpretación. Autores como Hathaway y Dent afirman que los requisitos de visados y las sanciones a los transportistas "pueden no violar el art. 33 directamente», pero «hacen aumentar el riesgo de devolución y, efectivamente, socavan el propósito fundamental de la Convención»" ${ }^{83}$.

Esta apreciación, hecha en la década de los setenta, fue sustentada posteriormente por la Asociación de Derecho internacional en 2002 cuando afirmó que «las Altas Partes contratantes asegurarán a todo aquel bajo su jurisdicción los derechos y las libertades definidos en la Sección Primera de la Convención» ${ }^{84}$, una idea que subscribió el ACNUR en la Opinión Consultiva de 2007, que orienta la discusión hacia la complementariedad entre los derechos humanos y el derecho de los refugiados ${ }^{85}$.

Es cierto que el art. 33 CG no contiene una limitación territorial explícita. A lo sumo, el art. 1(3) del Protocolo de 1967 prevé que este se aplicará por los Estados parte «sin limitación geográfica alguna». Lauterpacht y Bethlehem destacan que esta cláusula podría emplearse para apoyar la aplicabilidad extraterritorial del art. $33 \mathrm{CG}$, aunque reconocen que se trataba de una modificación de los términos del art. 1, B, 1 (a) CG, que se refería a los «acontecimientos ocurridos antes del 1 de enero de 1951, en Europa» ${ }^{86}$.

Puede aducirse que la aplicación extraterritorial del art. 33 CG provocaría de facto el derecho general a que toda solicitud fuera examinada. Ahora bien, la obligación del non-refoulement no equivale a un derecho de admisión de los solicitantes de asilo. Noll admite que el art. 33 CG podría comportar

81 ACNUR, Opinión Consultiva sobre la aplicación extraterritorial, loc. cit., supra nota 69.

82 Guy GOODWIN-GILL, Jane McADAM, The Refugee in International Law, Oxford University Press, Oxford, p. 385.

83 James HATHAWAY, John A. DENT, Refugee Rights: Report on a Comparative Survey, York Lanes Press, Toronto, 1995, pp. 5-17, p. 14.

84 Asociación de Derecho Internacional, Declaración de Estándares Mínimos para los Procedimientos de Refugio, Resolución 6/2002, de 6 de abril de 2002.

85

ACNUR, loc. cit., supra nota 69.

86 LAUTERPACHT y BETHLEHEM, op. cit., p. 114, párr. 84, supra nota 60. 
un derecho del refugiado a "transgredir una frontera administrativa», pero no comporta un derecho equivalente de acceder físicamente al territorio de dicho Estado $^{87}$. El hecho de que, en la práctica, los Estados posteriormente admitan a los solicitantes de asilo que se hallan en sus fronteras o en aguas internacionales bajo su jurisdicción para que inicien un proceso de asilo no equivale a un derecho de admisión general en el territorio ${ }^{88}$.

La dificultad estriba en determinar si el Estado lleva a cabo el acto de admisión o de rechazo en el ejercicio de su jurisdicción. El problema no es tanto si los actos u omisiones ocurren dentro del territorio del Estado, sino si puede afirmarse que se han llevado a cabo por o en nombre del Estado ${ }^{89}$. Por este motivo, es necesario esclarecer qué tipo de acto de control migratorio externalizado implica el ejercicio de la jurisdicción extraterritorial, es decir, cuándo se puede asociar la externalización con el ejercicio de competencias por parte del Estado.

Admitir que todo ejercicio de control migratorio necesariamente implica el ejercicio de la jurisdicción no es sostenible desde el punto de vista de la jurisprudencia del TEDH, órgano judicial que ha desarrollado esta última idea con una mayor profusión. Para empezar, el caso Soering no implicaba la aplicación extraterritorial del CEDH en sentido estricto, dado que el demandante se hallaba dentro del territorio británico. El elemento extraterritorial se producía porque los actos del Estado surtían efectos en territorio extranjero, en este caso, en Estados Unidos.

Cuando el Estado adopta la decisión dentro de su territorio, el control proviene del título formal del ejercicio de la soberanía territorial ${ }^{90}$. Cuando la decisión se toma fuera del territorio, el test para establecer dicho control -más aún cuando los Estados actúan con relación a los extranjeros- es más exigente. Así lo advierte el TEDH en el caso Bankovic y otros $c$. Bélgica cuando afirma que el artículo 1 del CEDH debe ser considerado como el reflejo de la noción de jurisdicción ordinaria y esencialmente territorial, siendo otras bases

87 Gregor NOLL, Negotiating Asylum: The EU Acquis, Extraterritorial Protection and the Common Market of Deflection, Martinus Nijhoff, Leiden, 2000, p. 387.

88 Thomas GAMMELTOFT-HANSEN, op. cit., p. 64, supra nota 65.

89 LAUTERPACHT, BETHLEHEM, op. cit., p. 160, supra nota 60.

90 Thomas GAMMELTOFT-HANSEN, «The Externalisation of European Migration Control and the Reach of International Refugee Law», en Elspeth GUILD; Paul MINDERHOUD, The First Decade of EU Migration and Asylum Law, Martinus Nijhoff, Leiden, 2012, pp. 273-298, p. 286. 
de jurisdicción excepcionales y que requieren una justificación especial en las circunstancias particulares de cada caso ${ }^{91}$.

El umbral en el que coloca el ejercicio de la jurisdicción la Sentencia Bankovic es más cercano al criterio territorial que a cualquier otro, lo que ha sido criticado e incluso desechado ${ }^{92}$. Sin embargo, la misma Sentencia admite que en determinadas circunstancias, aunque sean excepcionales, la jurisdicción se extiende extraterritorialmente ${ }^{93}$. Lo relevante es determinar bajo qué condiciones o criterios una situación cae bajo la jurisdicción del Estado. La jurisprudencia no es clara en la determinación de lo que significa «ejercicio de jurisdicción», dado que se apoya en elementos casuísticos a menudo insuficientes. En palabras del propio TEDH, «el control de facto da lugar a responsabilidades de iure» ${ }^{94}$, lo que Scheinin sintetiza diciendo: «[...] factivity creates normativity» ${ }^{95}$.

Esta perspectiva casuística, difícilmente predecible desde el punto de vista de la aplicabilidad del derecho, tiende a concretarse en torno a tres planos: la conexión entre el Estado y el territorio en el que tienen lugar los actos jurídicamente relevantes — criterio espacial o territorial—; la conexión entre el Estado y los individuos afectados por dichos actos — criterio personal—; y la conexión por la autoridad del agente estatal — tipo de acción del Estado— ${ }^{96}$.

91 TEDH (Gran Sala), Bankovic y otros c. Bélgica y otros, (dec.), núm. 52207/99, 12 de diciembre de 2001, apdo. 61.

92 John CERONE, "Out of Bounds? Considering the Reach of International Human Rights Law», Working Paper, núm. 5, Centre for Human Rights and Global Justice, New York University School of Law, Nueva York, 2006, p. 19-20; Javier GONZÁLEZ VEGA, «¿Enterrando a Bankovic? La eficacia extraterritorial del Convenio Europeo a la luz de la Sentencia TEDH (Gran Sala) de 20 de noviembre de 2014 en el asunto Jaloud c. Países Bajos», Revista Española de Derecho Internacional, vol. 67, 2017, pp. 312-317; y Ralph WILDE, «Opinion: 'The Legal Space' or 'Espace Juridique' of the European Convention on Human Rights: Is It Relevant to Extraterritorial State Action?», European Human Rights Law Review, núm. 2, 2005, pp. 115-124. GAMMELTOFT-HANSEN, op. cit., p. 287, supra nota 90.

94 TEDH, Al-Saadoon y Mufhi c. Reino Unido, núm. 61498/08, 30 de junio de 2009, apdo. 88.

95 Martin SCHEININ, «Extraterritorial Effect of the International Covenant on Civil and Political Rights", en Fons COOMANS et al. (eds.), Extraterritorial Application of Human Rights, Intersentia, Antwerp, 2004, pp. 73-81.

96 Ralph WILDE, «Compliance with Human Rights Norms Extraterritorially: Human Rights Imperialism?», en Laurence BOISSON DE CHAZOURNES (ed.), International Law and the Quest for its Implementation. Le droit international et la quête de 
La Sentencia del TEDH Hirsi Jama c. Italia identifica los rasgos del non-refoulement ante una circunstancia extraterritorial concreta ${ }^{97}$. El TEDH examinó la cuestión relativa a la aplicabilidad del art. 33 CG y su conexión con el art. 3 del CEDH. Declaró por unanimidad que la expulsión en alta mar de los veinticuatro solicitantes de asilo procedentes de Eritrea y de Somalia, y su envío a Libia en barcos militares italianos, tras haber sido interceptados en alta mar por la guardia italiana —a 35 millas al sur de Lampedusa-, violaba la obligación de non-refoulement ${ }^{98}$.

El Gobierno italiano sostuvo que no se trataba de un supuesto de expulsión de extranjeros, dado que estos no se encontraban dentro de las fronteras italianas, sino que era un supuesto de rechazo de entrada de extranjeros en su territorio y, por tanto, respetuoso con el derecho internacional. Sin embargo, el TEDH subrayó que los hechos ocurrieron en buques del ejército italiano, cuya tripulación estaba compuesta por personal militar italiano y, por tanto, los solicitantes se hallaban bajo el control exclusivo, de iure y de facto, de las autoridades italianas 99 .

El caso Hirsi se planteó cuando estaba vigente el Tratado Bilateral de Amistad, Asociación y Cooperación firmado entre Italia y Libia el 30 de agosto de 2008, en vigor desde el 2 de marzo de 2009. Como parte del acuerdo,

sa mise en oeuvre. Liber Amicorum Vera Gowlland-Debbas, Nijhoff, Leiden, 2010, pp. 315-344, p. 324.

97 Hirsi Jamaa y otros c. Italia, loc. cit., supra nota 61. Sobre esta, véase Dolores BOLLO AROCENA, "Push Back, expulsiones colectivas y non-refoulement. Algunas reflexiones a propósito de la Sentencia dictada por la Gran Sala del TEDH en el caso Hirsi Jamaa y otros contra Italia (2012)», en Santiago TORRES BERNÁRDEZ (coord.), El derecho internacional en el mundo multipolar del siglo XXI: obra homenaje al profesor Luis Ignacio Sánchez Rodríguez, Iprolex, Madrid, 2013 y en la misma obra, Juan Antonio CARRILLO SALCEDO, «Reflexiones en torno a la Sentencia del Tribunal Europeo de Derechos Humanos en el caso Hirsi Jamaa y otros contra Italia (Sentencia de 23 de febrero de 2012)», pp. 687-694; Claribel DE CASTRO, «TEDH. Sentencia de 23.02.2012 (Gran Sala). Hirsi Jamaa E. A. c. Italia 27765/09. El CEDH como límite de las políticas migratorias europeas», Revista de Derecho Comunitario Europeo, núm. 46, septiembre/diciembre 2013, pp. 1119-1135; y Francesco MESSINEO, "Yet another mala figura: Italy breached non-refoulement obligations by intercepting migrants' boats at sea, says EctHR», disponible en http://www.ejiltalk.org/yet-another-mala-figura-italy-breached-non-refoulement-obligations-by-intercepting-migrants-boats-at-sea-says-ecthr/ (consultado por última vez el 6.11.2016). Hirsi Jamaa, loc. cit., párrs. 134-135, supra nota 61.

Ibid., apdo. 81. 
Italia comprometía cinco mil millones de dólares durante los siguientes veinte años para proyectos de infraestructura libios. A cambio, Libia aceptaba recibir a los migrantes interceptados por Italia y autorizaba que patrullas conjuntas para el control migratorio actuaran en el mar territorial libio y que las propias autoridades libias ayudaran a frenar la migración irregular hacia Europa ${ }^{100}$. No obstante, el Tratado no justificaba que Italia fuera eximida de responsabilidad en el caso. Aún más, cuatro meses después de la Sentencia, el relator especial del comisario de derechos humanos del Consejo de Europa, en su visita a Italia, manifestó que la renegociación del acuerdo bilateral con Libia debía incluir garantías de respeto de los derechos humanos para evitar violaciones similares a las constatadas por el $\mathrm{TEDH}^{101}$.

A ello hay que añadir la vía de interpretación recientemente abierta por el abogado general Mengozzi sobre el alcance de la aplicación de la CDFUE. En el marco de la cuestión prejudicial sobre la denegación de visados humanitarios a una familia siria por parte de Bélgica, el abogado general Mengozzi se remite al art. $1 \mathrm{CEDH}$ para apreciar que este, efectivamente, contiene una "cláusula de jurisdicción» que funciona como un criterio de activación de la responsabilidad de los Estados parte en el CEDH. Sin embargo, dado que no figura una cláusula similar en la CDFUE, el único criterio que condiciona la aplicación de esta en lo que se refiere a la acción de los Estados se inscribe en su art. 51 (1). En palabras del abogado general, la cláusula de jurisdicción condiciona la aplicabilidad del CEDH, pero no afecta al alcance de la aplicación de la CDFUE, que viene determinado por su art. 51 (1), es decir, por la aplicación por los Estados del derecho de la UE ${ }^{102}$.

Finalmente, cabe referirse al caso J. H. A. c. España resuelto ante el Comité contra la Tortura, que trae causa en el acuerdo alcanzado entre el Gobierno español y el mauritano el 12 de febrero de 2007, que permitía el remolque del carguero Marine I a la costa mauritana de Nuadibú. Días antes, un remolcador español de salvamento marítimo había partido hacia Tenerife para atender la llamada de socorro enviada desde el carguero Marine I que había naufragado en aguas internacionales con 369 inmigrantes a bordo procedentes de África y

100 GAMMELTOFT-HANSEN, op. cit., p. 271, supra nota 89; y Silja KLEPP, «A Contested Asylum System: The European Union between Refugee Protection and Border Control in the Mediterranean Sea», European Journal of Migration and Law, núm. 12, 2010, pp. 1-21.

101 Comisario de Derechos Humanos del Consejo de Europa, Report by Nils Muiznieks following his visit to Italy from 3 to 6 July 2012, Comm DH (2012) 26, Estrasburgo, 2012, p. 3.

102 Conclusiones del abogado general Mengozzi, loc. cit., punto 97, supra nota 5. 
de Asia ${ }^{103}$. Un grupo de los inmigrantes desembarcados fueron trasladados a Canarias y el otro fue enviado a Cabo Verde en un avión fletado por España. El Estado sostuvo la ausencia de responsabilidad por haberse producido los hechos fuera de su jurisdicción. El Comité, sin embargo, observó que España mantuvo el control sobre las personas a bordo del Marine I desde el momento del rescate y durante todo el proceso de identificación y repatriación que tuvo lugar en Nouadhibou. Igualmente, el Comité apreció que España ejercía, en virtud del acuerdo diplomático firmado con Mauritania, un control de facto constante sobre las víctimas durante su detención en Nouadhibou. En consecuencia, las víctimas se encontraban sometidas a la jurisdicción de España en lo que se refería a la queja objeto de la presente comunicación ${ }^{104}$.

Por todo ello, una interpretación conforme a la cual el art. 33 CG solo se aplica dentro del territorio o en las fronteras del Estado no se ajusta a la tendencia jurisprudencial contemporánea. El énfasis en el criterio del ejercicio de la jurisdicción resulta ser el más acorde con la interpretación de otros tratados de derechos humanos.

\section{LA ESCASA DENSIDAD NORMATIVA DEL DERECHO A SALIR DEL PROPIO PAÍS}

Las medidas de externalización de los controles fronterizos de la UE y sus Estados miembros materializadas en acuerdos bilaterales o en acciones con terceros Estados se llevan a cabo en conjunción con las autoridades estatales de los territorios en los que tienen lugar dichos controles. Los Estados terceros han de adaptar su legislación, sus sistemas y sus prácticas con el fin de alcanzar los objetivos previstos. Los desarrollos legislativos que puedan preverse, incluso las propias acciones conjuntas entre Estados, repercuten directamente en el ejercicio del derecho a salir del propio país.

La inclusión de tal derecho en la Declaración Universal de los Derechos Humanos de 1948 respondió a dos tipos de intereses: por un lado, el ímpetu inmediato por incorporarlo provenía de la restricción de la libertad

103 Comité Contra la Tortura, J. H. A. c. España, 21 noviembre 2008, Comunicación 323/2007, CAT/C/41/D323/2007, párrs. 2.1 y 6.1

${ }^{104}$ Ibid., apdo. 8.2. El autor de la Comunicación alegaba la comisión de torturas en el sentido del art. 1 del Convenio contra la Tortura, así como la violación del art. 3, ya que en caso de que los inmigrantes fueran devueltos, se verían sujetos a torturas o tratos crueles, inhumanos o degradantes teniendo en cuenta la situación de conflicto en Cachemira. 
de circulación provocada por el contexto de la Segunda Guerra Mundial; por otro lado, desde un punto de vista más amplio, era una expresión más de la libertad civil individual ${ }^{105}$. Posteriormente, fue reconocido en el Pacto de Derechos Civiles y Políticos de 1966 (PDCP) como un derecho que corresponde a "todos», a los nacionales y a los extranjeros ${ }^{106}$. Sin embargo, pese a su enunciado, se trata de un «derecho incompleto» en la medida en que no está emparejado con el deber del Estado de admitir a quien ejerce el derecho a salir de su propio país. La primera debilidad, por tanto, consiste en que el derecho a salir del país no conlleva automáticamente el derecho a entrar en otro país.

Otras limitaciones de este derecho están presentes tanto en el ordenamiento internacional como en el de la UE. La regulación internacional presta una intensa atención a las irregularidades de los movimientos ${ }^{107}$. La migración irregular se denomina así porque tiene lugar en contravención con las normas, bien del Estado de origen, bien del Estado de tránsito, bien del Estado de destino; es decir, se produce sin la preceptiva autorización, porque el migrante carece de pasaporte, de visado o de otros documentos de viaje necesarios o porque no reúne los requisitos administrativos para salir del país ${ }^{108}$. De modo que el derecho a solicitar asilo y el principio de non-refoulement representan, de hecho, limitadas incursiones en el poder soberano de los Estados para determinar quién puede cruzar sus fronteras y permanecer dentro de ellas ${ }^{109}$. En esta línea, el derecho a salir del propio país, en palabras de Goodwin-Gill, «nunca ha sido considerado

105 Jane McADAM, «An Intellectual History of Freedom of Movement in International Law: The Right to Leave as a Personal Liberty», Melbourne Journal of International Law, núm. 12, 2011, pp. 27-56. Interesa recordar que numerosos redactores de la DUDH eran emigrantes.

106 Art. 12 (2) del PDCP. Pese a que Robert Jennings y Arthur Watts mantienen que la emigración es «en principio un asunto que corresponde enteramente a la legislación interna de los Estados», asumen que el derecho a emigrar ha sido reconocido en una serie de instrumentos internacionales. Robert JENNINGS y Arthur WATTS (eds.), Oppenheim's International Law, Longman, London, 9. a ed., 1992, p. 381.

107 Satvinder S. JUSS, «Free Movement and the World Order», International Refugee Law, núm. 16 (3), 2004, p. 292.

108 Según el término «migración irregular» consultado en la página web de la Organización Internacional para las Migraciones, disponible en http://www.iom.int/key-migration-terms (consultado por última vez el 1.11.2016).

109 McADAM, op. cit., p. 29, supra nota 105. 
un derecho absoluto» ${ }^{110}$. Pese a que las particulares restricciones de los Estados varían, la práctica actual muestra la tendencia contraria a la emergencia del principio general de la libertad de circulación y, más concretamente, del derecho a salir del país. La CDFUE, sin ir más lejos, no lo recoge, tan solo se refiere a la libertad de circulación de los ciudadanos de la UE y de los nacionales de terceros países que residan legalmente en el territorio de los Estados miembros. No obstante, en tanto que Estados parte del PDCP, los Estados miembros de la UE se ven abocados a respetarlo.

En concreto, la pregunta que se plantea después de estudiar las medidas de externalización del control migratorio es si estas podrían constituir una restricción del derecho a salir del propio país ${ }^{111}$. Aunque tal derecho se proclama en el art. 12 (2) PDCP en términos universales («Toda persona tendrá derecho a salir libremente de cualquier país, incluso del propio»), a continuación el mismo precepto prevé que el derecho puede ser objeto de «restricciones previstas por ley, siempre que sean necesarias para proteger la seguridad nacional, el orden público, la salud o la moral públicas o los derechos y libertades de terceros, y sean compatibles con los demás derechos reconocidos en el presente Pacto» ${ }^{112}$. No provee más detalles sobre la naturaleza de estas limitaciones, pero, indudablemente autoriza al Estado a restringir el derecho ${ }^{113}$. Obviamente, las restricciones a salir del propio país pueden justificarse con relación a quienes tratan de eludir el cumplimiento del derecho interno (comparecer ante los tribunales, cumplir una Sentencia o pagar los impuestos), pero además de esto, el PDCP concede un amplio margen al Estado.

De hecho, inicialmente se planteó recoger un listado de razones por las cuales podría restringirse la libertad de circulación, entre las que se encontraba

${ }^{110}$ Guy GOODWIN-GILL, «The Right to Leave, the Right to Return and the Question of the Right to Remain», en Vera GOWLLAND-DEBBAS (ed.), The Problem of Refugees in the Light of Contemporary International Law Issues: Papers Presented at the Colloquium Organized by the Graduate Institute of International Studies in Collaboration with the Office of the United Nations High Commissioner for Refugees, 26 y 27 de mayo de 1994, Martinus Nijhoff, Ginebra, Leiden, 1995, pp. 93 y 96.

111 Contemplado en el art. 12 del PDCP, en el art. 8 del Convenio Internacional sobre los Trabajadores Migrantes, en el art. 5 del Convenio sobre la Eliminación de Todas las Formas de Discriminación Racial y en el art. 10 del Convenio sobre Derechos del Niño.

112 Art. 12.3 PDCP.

${ }^{113} \mathrm{El}$ art. 2 del Protocolo 4 del CEDH recoge el derecho en líneas muy similares. 
la de ayudar a los Estados vecinos a controlar la migración ${ }^{114}$. Sin embargo, finalmente se optó por indicar tan solo razones generales, así como los requisitos que ha de reunir la restricción, entre los que destaca el que haya de establecerse por ley. Esto significa que la restricción del derecho a salir del país ha de preverse conforme a una norma parlamentaria general o acto equivalente y que habrá de ser accesible.

En este marco, el Comentario General 27 del Comité de Derechos Humanos sobre el alcance del derecho a salir del propio país advirtió que los Estados deben incluir información sobre los recursos disponibles cuando limiten el derecho a salir del propio territorio. Al mismo tiempo, consideró sumamente importante que los Estados informen de todas las restricciones jurídicas y prácticas que aplican al derecho de salida, tanto a nacionales como a extranjeros ${ }^{115}$.

Entre otros, el Comité examinó indirectamente las restricciones al derecho a salir del país en el caso Ismet Celepli c. Suecia en el que el demandante, un kurdo procedente de Turquía, solicitó el estatus político de refugiado en Suecia ${ }^{116}$. Pese a que las autoridades suecas inicialmente le permitieron permanecer en el país, decretaron su expulsión por sus supuestas actividades terroristas. Sin embargo, la expulsión no se ejecutó como consecuencia de la aplicación del non-refoulement. En su lugar, las autoridades suecas optaron por controlar los movimientos del demandante y su lugar de residencia. Suecia adujo que las restricciones a la libertad de circulación se justificaban, dado que estaban «previstas por la ley y eran necesarias para la protección de la seguridad nacional y el orden público»" ${ }^{117}$. El Comité admitió que las restricciones debidas a la seguridad nacional proyectadas sobre la libertad de circulación del demandante no violaban el art.12 PDCP.

El TEDH también aporta elementos de interpretación sobre la libertad de circulación a la luz del art. 2 del Protocolo 4 CEDH. En el caso Stamose c. Bulgaria el demandante había sido deportado de Estados Unidos y enviado a Bulgaria porque había finalizado su permiso de estancia en aquel país ${ }^{118}$. El TEDH cuestionaba si era proporcionado que Bulgaria prohibiera automáticamente al demandante viajar a cualquier país extranjero bajo el argumento

${ }^{114}$ Manfred NOVAK, U. N. Covenant on Civil and Political Rights. CCPR Commentary, 2. ${ }^{a}$ ed., Engel, Kehl am Rhein, 2005, p. 270.

115 Comité de Derechos Humanos, Comentario General núm. 27, Libertad de circulación (art. 12), CCPR/C/21/Rev.1/Add.9, 2 de noviembre de 1999, párrs. 3, 10-18.

116 Comité de Derechos Humanos, Ismet Celepli c. Suecia, Comunicación núm. 456/1991, 24 de julio de 1994, CCPR/C/51/D/456/1991.

${ }^{117}$ Ibid., apdo. 4.2.

118 TEDH, Stamose c. Bulgaria, núm. 29713/05, 27 de noviembre de 2012. 
de haber infringido la ley de inmigración de Estados Unidos. El Tribunal de Estrasburgo estimó que no podía considerar proporcional una medida tan amplia e indiscriminada ${ }^{119}$. Las consecuencias normales de una infracción a las normas de inmigración de un país deberían ser, respecto de la persona afectada, la expulsión de dicho país y la prohibición de volver a entrar por un determinado período de tiempo. Parece excesivamente severo por parte del Estado búlgaro - que no es el directamente afectado por la infracción cometida por el demandante - el prohibirle viajar a cualquier otro país extranjero por un período de dos años ${ }^{120}$.

Este análisis muestra que el derecho a salir del propio país posee un significado en el orden internacional y que sus excepciones han de estar debidamente justificadas. Las restricciones en blanco, los requisitos que no se ajustan a la legalidad o las limitaciones inconsistentes con otros derechos no están permitidas.

En este orden de cosas, los acuerdos bilaterales firmados por los Estados constituyen un motivo de preocupación para el Tribunal de Estrasburgo. Recientemente, en la Sentencia de la Gran Sala Khlaifia c. Italia relativa a la detención y posterior expulsión de tres demandantes tunecinos a Túnez tras haber desembarcado en Italia, el Gobierno italiano alegó que el Acuerdo Bilateral firmado entre Italia y Túnez podría considerarse una base legal para retener a los solicitantes en Lampedusa a la espera de su retorno ${ }^{121}$. Sin embargo, el Tribunal estimó que ninguna forma de expulsión colectiva e indiscriminada podría justificarse bajo la forma de un acuerdo bilateral ${ }^{122}$. La devolución se llevaría a cabo a través de un procedimiento simplificado, que implicaba la mera identificación de las personas afectadas por las autoridades consulares tunecinas, sin ninguna mención a sus específicas. Además de las propias circunstancias de los implicados, el Tribunal de Estrasburgo llamó la atención sobre el hecho de que el acuerdo no se hubiera publicado. El Tribunal no pudo determinar si el acuerdo proveía de suficientes garantías. Sus consecuencias, por tanto, eran imprevisibles ${ }^{123}$.

119 Ibid., apdo. 33.

120 Ibid., apdo. 34.

${ }^{121}$ El objeto del Acuerdo entre Túnez e Italia, firmado el 5 de abril de 2011, consistía en reforzar los controles fronterizos y facilitar el retorno de migrantes irregulares a Túnez mediante un procedimiento simplificado.

122 TEDH (Gran Sala) Khlaifia c. Italia, núm. 16483/12, 15 de diciembre de 2016, párrs. 83 y 216.

123 Ibid., párrs. 37, 57 y 102. 


\section{CONCLUSIONES}

La fuerza que está adquiriendo la dimensión externa de la UE como una solución al problema migratorio confirma que es en esta dimensión en la que confluyen los intereses de los Estados miembros para dar respuesta al problema. En efecto, por medio de las políticas de visados, la escisión de territorios, las interceptaciones en el mar y los acuerdos bilaterales, los Estados y la UE construyen un nuevo tipo de control migratorio que mira hacia el exterior. La vocación última es gestionar la entrada de nacionales de terceros países cuando estos aún se hallan en sus Estados de origen o de tránsito. Esto excede la pura gestión, ya que permite controlar los flujos migratorios en un sentido amplio.

La consecuencia directa en el orden de los derechos de los potenciales solicitantes de asilo es que se los priva de la posibilidad de invocar el non-refoulement. Es decir, en el marco de este nuevo tipo de control, el solicitante de asilo que busca protección internacional se halla fuera del orden legal ordinario de la CG, por lo que a los efectos de dicho tratado su estatus jurídico es indeterminado ${ }^{124}$.

De la CG subyace la idea de que la vinculación del refugiado con el Estado en el que solicita asilo se produce desde el momento en el que este se halla fuera de su país y, por lo tanto, es el Estado de destino el que ha de protegerlo. Se produce una desvinculación física del refugiado con el territorio de origen y, a su vez, una vinculación con el Estado de destino. Sin embargo, cuando es el Estado de origen el que ejerce el control sobre los individuos que pretenden huir de su territorio, pero aún no han salido, estos difícilmente pueden apelar al non-refoulement.

Este contexto de transformación de las prácticas del Estado en materia de control de los flujos migratorios conlleva la necesaria revisión de los tipos de control. Así, en la actualidad, las formas de control migratorio se desarrollan en tres planos: a) el control realizado en el territorio del Estado o en sus fronteras, en cuyo caso la jurisdicción ejercida por el Estado es territorial y entonces el principio de non-refoulement se aplica conforme al estándar ordinario; $b$ ) el control llevado a cabo en alta mar, en cuyo caso las funciones y la jurisdicción del Estado se conciben como extraterritoriales y también rige el principio de non-refoulement; $\mathrm{y} c$ ) el control que ejerce un tercer Estado sobre la base de un acuerdo de asociación u otras medidas de externalización similares, en cuyo caso habría que determinar si es únicamente el Estado de origen el que ejerce

${ }^{124}$ Consejo de Derechos Humanos, Report of the Special Rapporteur on the Human Rights of Migrants, supra nota 12 . 
su jurisdicción territorial, ante la que el individuo podría invocar el derecho a salir del propio país con los límites que el mismo tiene en su interpretación contemporánea. En este plano, el instrumento que apenas se ha desarrollado es el visado humanitario, cuyo potencial proviene del hecho de que la embajada del Estado al que se solicita dicho visado ha de aplicar el propio Código de Visados y, a su vez, la CDFUE.

Por otro lado, en el marco de los acuerdos de asociación se suscita la cuestión sobre las condiciones en las que los Estados de origen de los refugiados asumen sus compromisos, aun cuando exista la manifestación jurídica del consentimiento y, por tanto, de la soberanía. La apelación a la cooperación al desarrollo, un aspecto presente ya en los acuerdos migratorios, envuelve un «discurso positivo de legitimación cuyo interés es implicar también a los países de origen, de tránsito y fronterizos», que ahora se extiende al ámbito del refugio ${ }^{125}$.

Hemos señalado también la necesidad de distinguir entre dos fenómenos estrechamente relacionados pero distintos: la externalización y el ejercicio de la jurisdicción extraterritorial. En la jurisprudencia del TEDH, se identifican soluciones extraterritoriales cuando el ejercicio del control se realiza sobre buques extranjeros en alta mar. Sin embargo, aún no existe una respuesta jurídica predecible respecto del marco de los acuerdos migratorios adoptados en el seno de la UE. La posición mantenida por el abogado general Mengozzi ofrece una nueva línea de interpretación sobre el ámbito de aplicación de la CDFUE. Dadas las pocas similitudes entre el CEDH y la CDFUE en lo que se refiere a la cláusula de jurisdicción y al criterio de activación de la responsabilidad de los Estados, inexistente en la CDFUE, el abogado general identifica un criterio propio y autónomo y determina que la norma aplicable es el art. 51 (1) CDFUE, es decir, las disposiciones de la CDFUE son aplicables a los Estados miembros cuando apliquen el derecho de la UE, al margen de criterios territoriales o extraterritoriales. Ciertamente, este criterio puede ser objetivado en mayor medida que los criterios de extraterritorialidad aportados por el TEDH, lo que abre nuevas reflexiones para el futuro.

Si el problema migratorio se centra en la pregunta central sobre las razones por las que huyen los migrantes, la respuesta es la pobreza y los conflictos armados. Ante ello, no es de extrañar que los acuerdos de cooperación recobren sentido y vitalidad. Pero, incluso en tal caso, la fuerza evocadora de los términos de la persecución y de la protección contenida en el principio de no devolución lo convierten en el principio no solo inspirador, sino también

125 Sami NAÏR, Frente a la catástrofe humanitaria, una solución real, Crítica, Barcelona, 2016, p. 43. 
útil, para pensar en un posible examen preliminar sobre los motivos por los que el solicitante busca protección internacional, aunque no haya salido de su país. Así, los valores que subyacen al principio de non-refoulement, reconocido como un elemento del acervo comunitario, se proyectarían hacia el exterior de la UE. 